\title{
Variation of the Chain Geometry in Isomeric 1D Co(NCS) Coordination Polymers and Their Influence on the Magnetic Properties
}

Michael Böhme, ${ }^{\dagger}$ Aleksej Jochim, ${ }^{\ddagger}$ Michał Rams,, Thomas Lohmiller, ${ }^{\&}$

Stefan Suckert, ${ }^{\ddagger}$ Alexander Schnegg, ${ }^{\|, \&}$ Winfried Plass, ${ }^{\dagger, *}$ and Christian Näther ${ }^{\ddagger, *}$

† Institute of Inorganic and Analytical Chemistry, Friedrich Schiller University Jena, Humboldtstraße 8, 07743 Jena, Germany.

* Institute of Inorganic Chemistry, Kiel University, Max-Eyth-Straße 2, 24118 Kiel, Germany.

$\S$ Institute of Physics, Jagiellonian University, Łojasiewicza 11, 30-348 Krakow, Poland.

${ }^{\&}$ EPR4Energy Joint Lab, Department Spins in Energy Conversion and Quantum Information Science. Helmholtz-Zentrum Berlin für Materialien und Energie GmbH, Kekuléstr. 5, 12489

Berlin, Germany.

'EPR Research Group, MPI for Chemical Energy Conversion, Stiftstraße 34-36, 45470

Mülheim an der Ruhr, Germany. 
Figure S1 $\quad$ IR spectrum of compound $1 . \quad 4$

Figure S2 IR spectrum of compound 2 .

Figure S3 IR spectrum of compound 3C.

Figure S4 IR spectrum of compound 3L. 5

Table S1 Selected crystal parameters and details of the structure refinements 6

Figure S5 Crystal structure of compound 1 with labeling and displacement ellipsoids 7 drawn at the $50 \%$ probability level.

$\begin{array}{lll}\text { Table S2 } & \text { Selected bond lengths and angles for compound } 1 & 7\end{array}$

Figure S6 Crystal structure of compound $\mathbf{2}$ with labeling and displacement ellipsoids 8 drawn at the $50 \%$ probability level.

Table S3 Selected bond lengths and angles for compound $2 \quad 8$

Figure S7 Crystal structure of compound $\mathbf{2}$ with view along the $a$-axis. 9

Figure S8 Crystal structure of compound $3 \mathrm{C}$ with labeling and displacement ellipsoids $\quad 10$ drawn at the $50 \%$ probability level.

Figure S9 Crystal structure of compound $\mathbf{3 L}$ with labeling and displacement ellipsoids $\quad 10$ drawn at the $50 \%$ probability level.

Table S4 Bond lengths and angles for compound 3C and 3L $\quad 11$

Figure S10 Arrangement of the chains in the crystal structure of $3 \mathrm{C}$ and $\mathbf{3 L} . \quad 12$

$\begin{array}{lll}\text { Figure S11 Experimental and calculated XRPD pattern of 3C. } & 13\end{array}$

Figure S12 Experimental and calculated XRPD pattern of 3L obtained from solution. 13

$\begin{array}{lll}\text { Figure S13 Experimental and calculated XRPD pattern of } 1 . & 14\end{array}$

$\begin{array}{lll}\text { Figure S14 Experimental and calculated XRPD pattern of } 2 . & 14\end{array}$

Figure S15 DTA, TG, and DTG curves as well as heating rate dependent measurements 15 for 1.

Figure S16 Experimental XRPD pattern of the residue obtained by thermogravimetric 15 measurements of $\mathbf{1}$ and $\mathbf{2}$ together with the calculated pattern of $\mathbf{3 L}$.

Figure S17 DTA, TG, and DTG curves as well as heating rate dependent measurements 16 for 2.

Figure S18 Experimental XRPD pattern of the residue obtained by annealing of 2 and 17 calculated XRPD pattern of $\mathbf{3 L}$.

Figure S19 Calculated XRPD pattern of 3C and 3L together with the experimental 17 pattern of a mixture of both isomers and after stirring this mixture in methanol for 5 days.

Figure S20 Calculated XRPD pattern of $\mathbf{3 C}$ and $\mathbf{3 L}$ together with the experimental pattern of a mixture of both isomers and after stirring this mixture in ethanol for 5 days.

Figure S21 DSC curve of $\mathbf{3 C}$ and $\mathbf{3 L}$ at $10^{\circ} \mathrm{C} / \mathrm{min}$. 
Figure S22 Temperature dependent XRPD measurements of 3C.

Figure S23 Temperature dependent XRPD measurements of $2 . \quad 19$

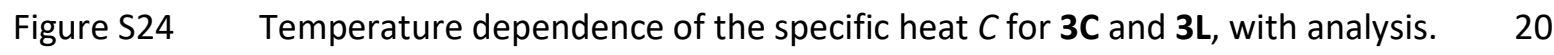

Figure S25 Magnetization of $\mathbf{3 C}$ and $\mathbf{3 L}$ (dots) measured at $1.8 \mathrm{~K}$. 20

Figure S26 The derivative of low-field susceptibility, as used to determine the critical 21 temperature of the antiferromagnetic phase of $\mathbf{3 L}$.

Figure S27 Ac magnetic susceptibility measured for $3 \mathrm{~L}$ at $2 \mathrm{~K}$ and different applied dc $\quad 21$

Figure S28 BS-DFT computational models 3C-Co1Co2 and 3L-Co1Co2. 22

Table S5 BS-DFT results for 3C-Co1Co2 and 3L-Co1Co2 22

Figure S29 BS-DFT obtained spin densities for 3C-Co1Co2 and 3L-Co1Co2. 23

Figure S30 Overlay of the $\left[\mathrm{CO}_{2}(\mathrm{NCS})_{2}\right]^{2+}$ cores as found in $\mathbf{3 C}$ and $\mathbf{3 L}$. 23

Figure S31 Ab initio computational models 3C-Co1, 3C-Co2, 3L-Co1, and 3L-Co2. 24

Table S6 Relative CASSCF energies for the crystallographically independent cobalt(II) $\quad 25$ centers in $\mathbf{3 C}$ and $\mathbf{3 L}$

Table S7 Relative CASPT2 energies for the crystallographically independent cobalt(II) 26 centers in $\mathbf{3 C}$ and $\mathbf{3 L}$

Table S8 Relative RASSI-SO energies of the ${ }^{4} \mathrm{~T}_{1 \mathrm{~g}}$ ground multiplet for the 26 crystallographically independent cobalt(II) centers in $\mathbf{3 C}$ and $\mathbf{3 L}$

Figure S32 Representation of the magnetic axes for the ground state Kramers doublet 27 in $\mathbf{3 C}$ and $\mathbf{3 L}$.

Figure S33 Overlay of the mononuclear cobalt(II) computational models 3C-Co2 and 3LCo1.

Scheme S1 Graphical definition of 12 -membered spin rings of the type $[\cdots A \cdots B \cdots C \cdots D \cdots]_{3}$ to simulate hypothetical chains.

Figure S34 Depiction of spin states as obtained by POLY_ANISO simulations for 3C. 


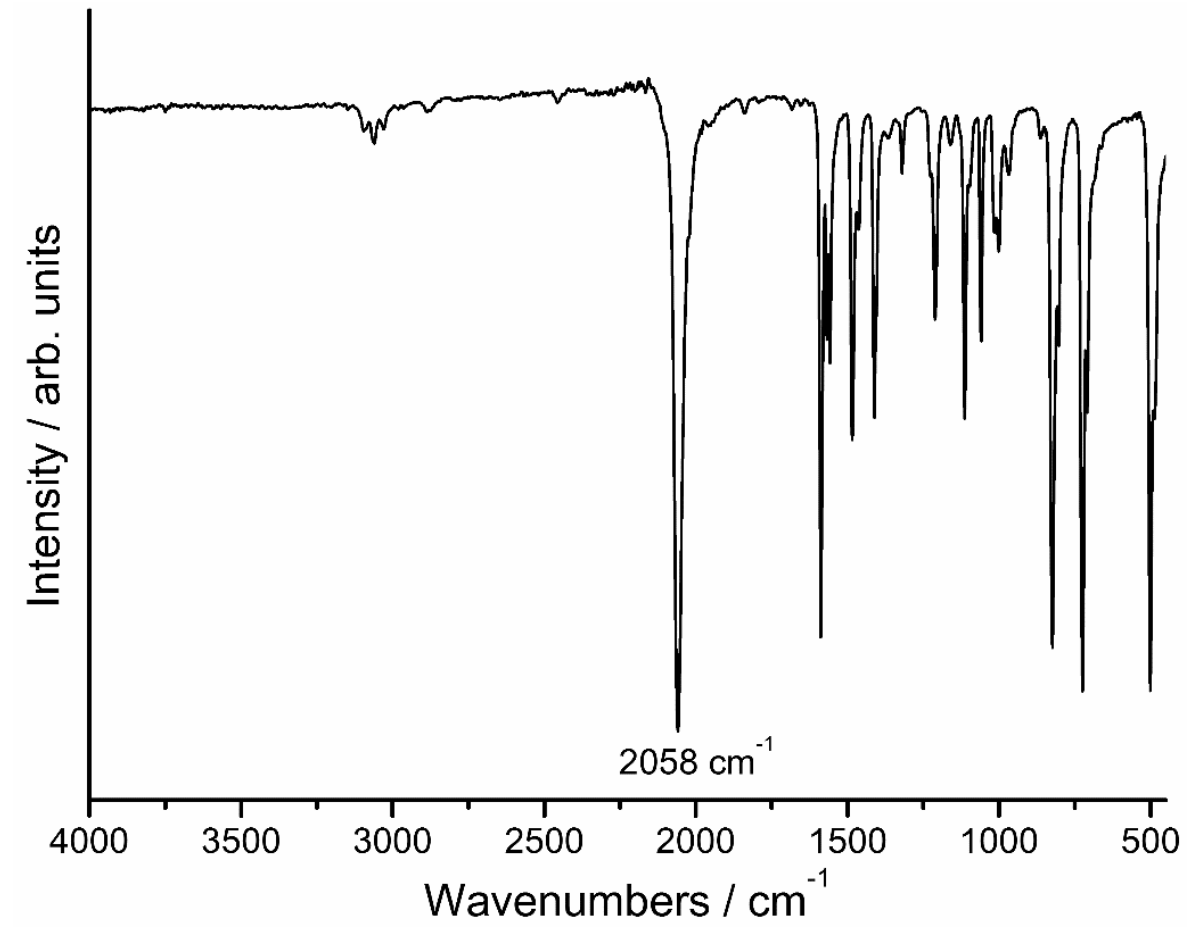

Figure S1. IR spectrum of 1. Given are the values for the $\mathrm{CN}$ stretching vibrations of the thiocyanato ligand.

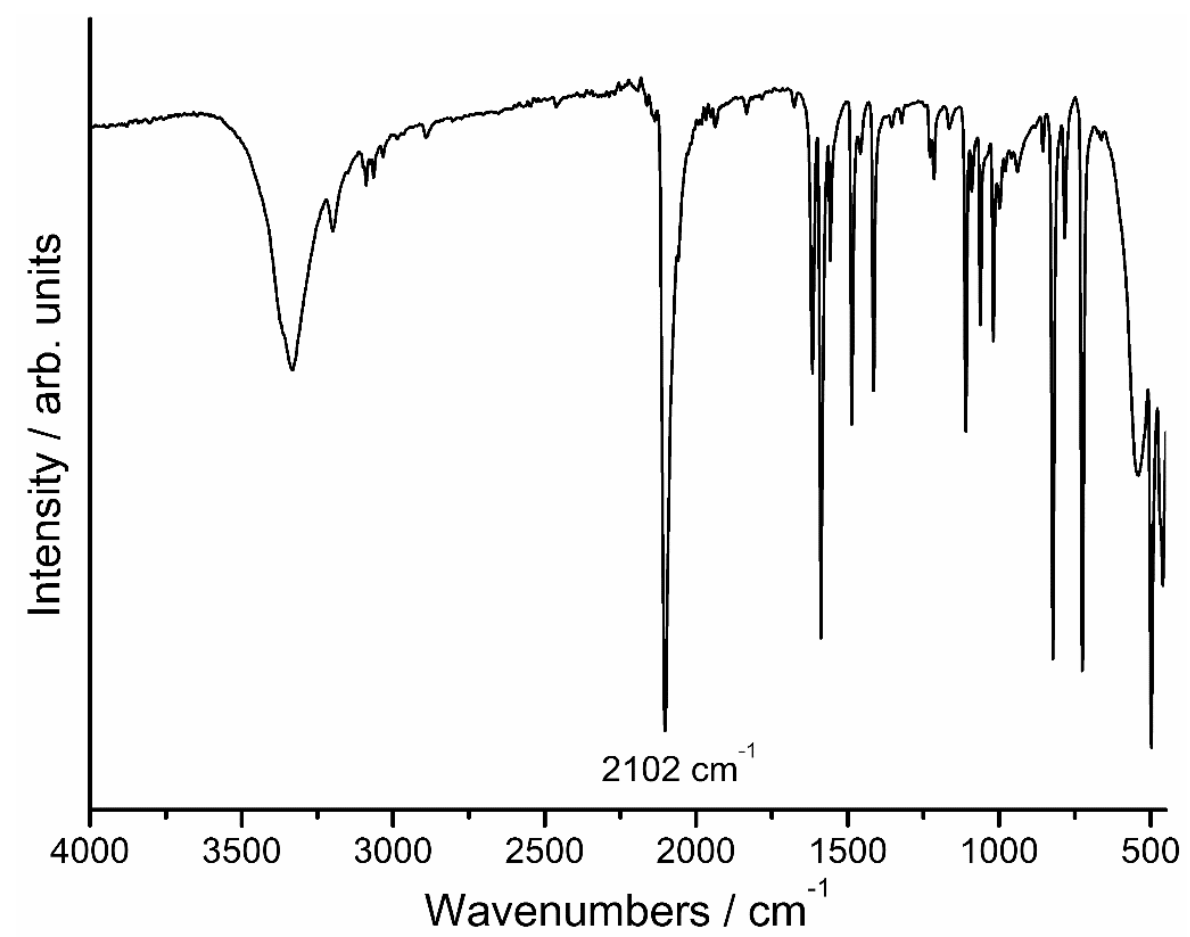

Figure S2. IR spectrum of 2. Given are the values for the $\mathrm{CN}$ stretching vibrations of the thiocyanato ligand. 


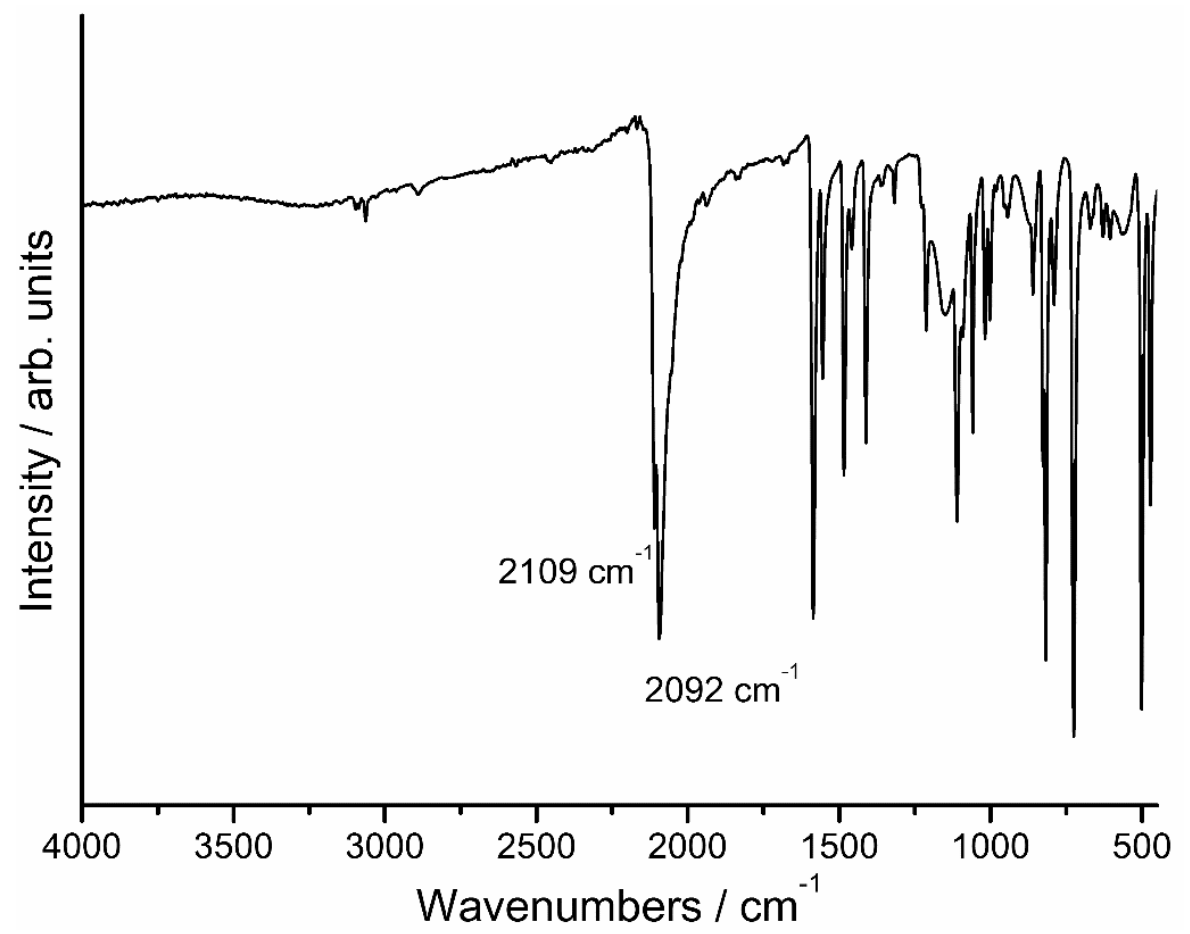

Figure S3. IR spectrum of 3C. Given are the values for the CN stretching vibrations of the thiocyanato ligand.

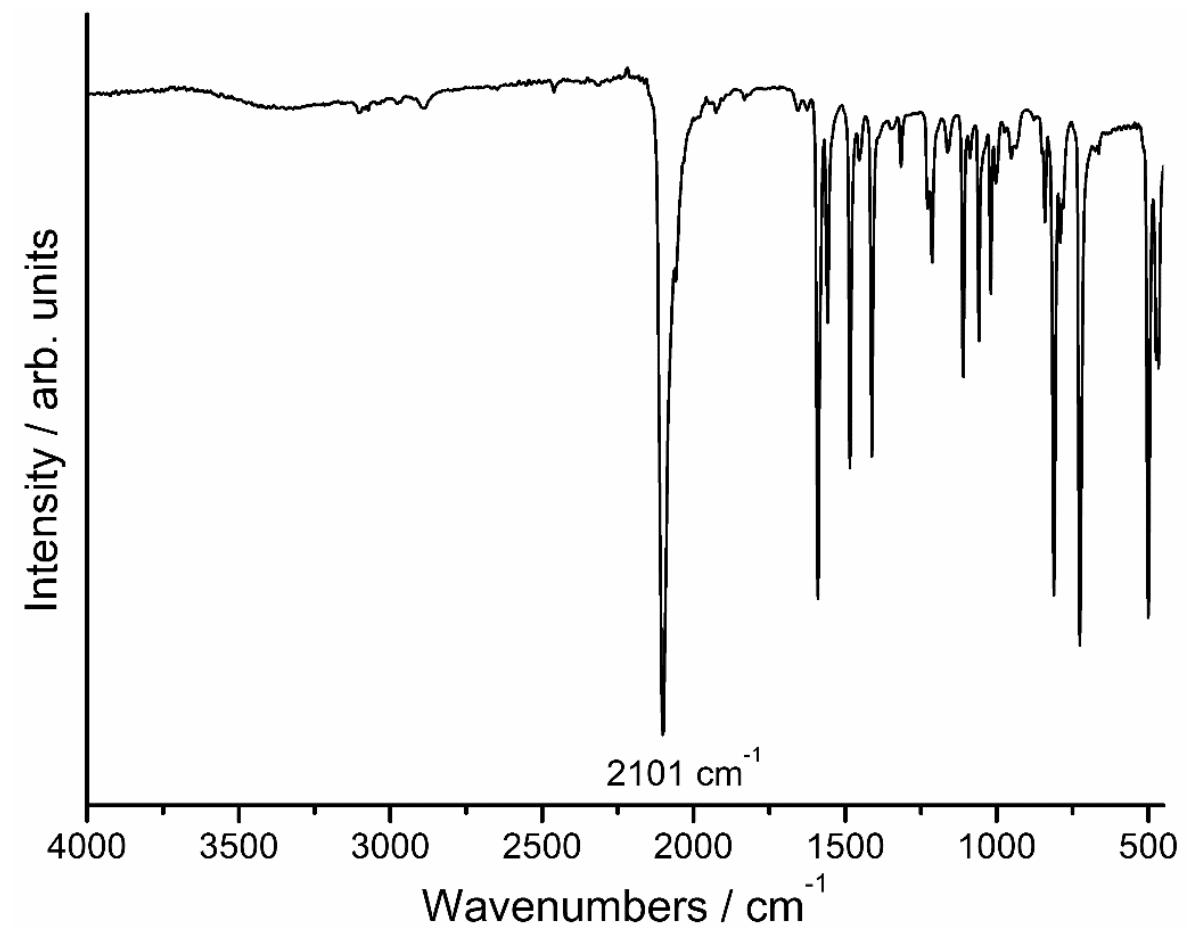

Figure S4. IR spectrum of 3L. Given are the values for the CN stretching vibrations of the thiocyanato ligand. 
Table S1. Selected crystal parameters and details of the structure refinements for $\mathbf{1}, \mathbf{2}, \mathbf{3 C}$, and $\mathbf{3 L}$

\begin{tabular}{|c|c|c|c|c|}
\hline compound & 1 & 2 & $3 C$ & $3 L$ \\
\hline Formula & $\mathrm{C}_{22} \mathrm{H}_{16} \mathrm{Cl}_{4} \mathrm{CoN}_{6} \mathrm{~S}_{2}$ & $\mathrm{C}_{12} \mathrm{H}_{12} \mathrm{Cl}_{2} \mathrm{CoN}_{4} \mathrm{O}_{2} \mathrm{~S}_{2}$ & $\mathrm{C}_{12} \mathrm{H}_{8} \mathrm{Cl}_{2} \mathrm{CoN}_{4} \mathrm{~S}_{2}$ & $\mathrm{C}_{12} \mathrm{H}_{8} \mathrm{Cl}_{2} \mathrm{CoN}_{4} \mathrm{~S}_{2}$ \\
\hline $\mathrm{MW} / \mathrm{g} \mathrm{mol}^{-1}$ & 629.26 & 438.21 & 402.17 & 402.17 \\
\hline crystal system & Trigonal & Monoclinic & Monoclinic & Triclinic \\
\hline space group & $R \overline{3}$ & $P 2_{1} / c$ & $C 2 / c$ & $P \overline{1}$ \\
\hline$a / \AA$ & $26.1440(8)$ & $10.4167(4)$ & $20.3687(11)$ & $8.0830(5)$ \\
\hline$b / \AA$ & $26.1440(8)$ & $12.1079(4)$ & $8.8343(5)$ & $9.3935(6)$ \\
\hline$c / \AA$ & $11.2720(4)$ & $7.5528(3)$ & 18.9769(9) & $10.7022(7)$ \\
\hline$\alpha /^{\circ}$ & 90 & 90 & 90 & $73.445(5)$ \\
\hline$\beta /{ }^{\circ}$ & 90 & $108.135(3)$ & $115.790(5)$ & $83.196(5)$ \\
\hline$\gamma /{ }^{\circ}$ & 120 & 90 & 90 & $80.791(5)$ \\
\hline$V / \AA^{3}$ & $6672.3(5)$ & $905.27(6)$ & $3074.6(3)$ & $766.59(8)$ \\
\hline$T / \mathrm{K}$ & $170(2)$ & $170(2)$ & $200(2)$ & $290(2)$ \\
\hline$Z$ & 9 & 2 & 8 & 2 \\
\hline$D_{\text {calc }} / \mathrm{g} \mathrm{cm}^{-3}$ & 1.409 & 1.608 & 1.738 & 1.742 \\
\hline$\mu / \mathrm{mm}^{-1}$ & 1.102 & 1.484 & 1.731 & 1.735 \\
\hline$\theta_{\max } / \mathrm{deg}$ & 26.002 & 25.749 & 27.095 & 28.01 \\
\hline measured refl. & 13400 & 11310 & 14917 & 11964 \\
\hline unique refl. & 2924 & 1734 & 3397 & 3704 \\
\hline refl. $[I>2 \sigma(I)]$ & 2431 & 1620 & 2660 & 2672 \\
\hline parameter & 160 & 106 & 193 & 193 \\
\hline$R_{\text {int }}$ & 0.0299 & 0.0299 & 0.0567 & 0.0667 \\
\hline$R_{1}[I>2 \sigma(I)]$ & 0.0436 & 0.0197 & 0.0391 & 0.0604 \\
\hline$w R_{2}$ [all data] & 0.1020 & 0.0504 & 0.0947 & 0.0975 \\
\hline GOF & 1.060 & 1.095 & 1.024 & 1.168 \\
\hline$\Delta \rho_{\max / \min } /$ e $\AA^{-3}$ & $0.463 /-0.451$ & $0.270 /-0.211$ & $0.398 /-0.487$ & $0.519 /-0.423$ \\
\hline
\end{tabular}




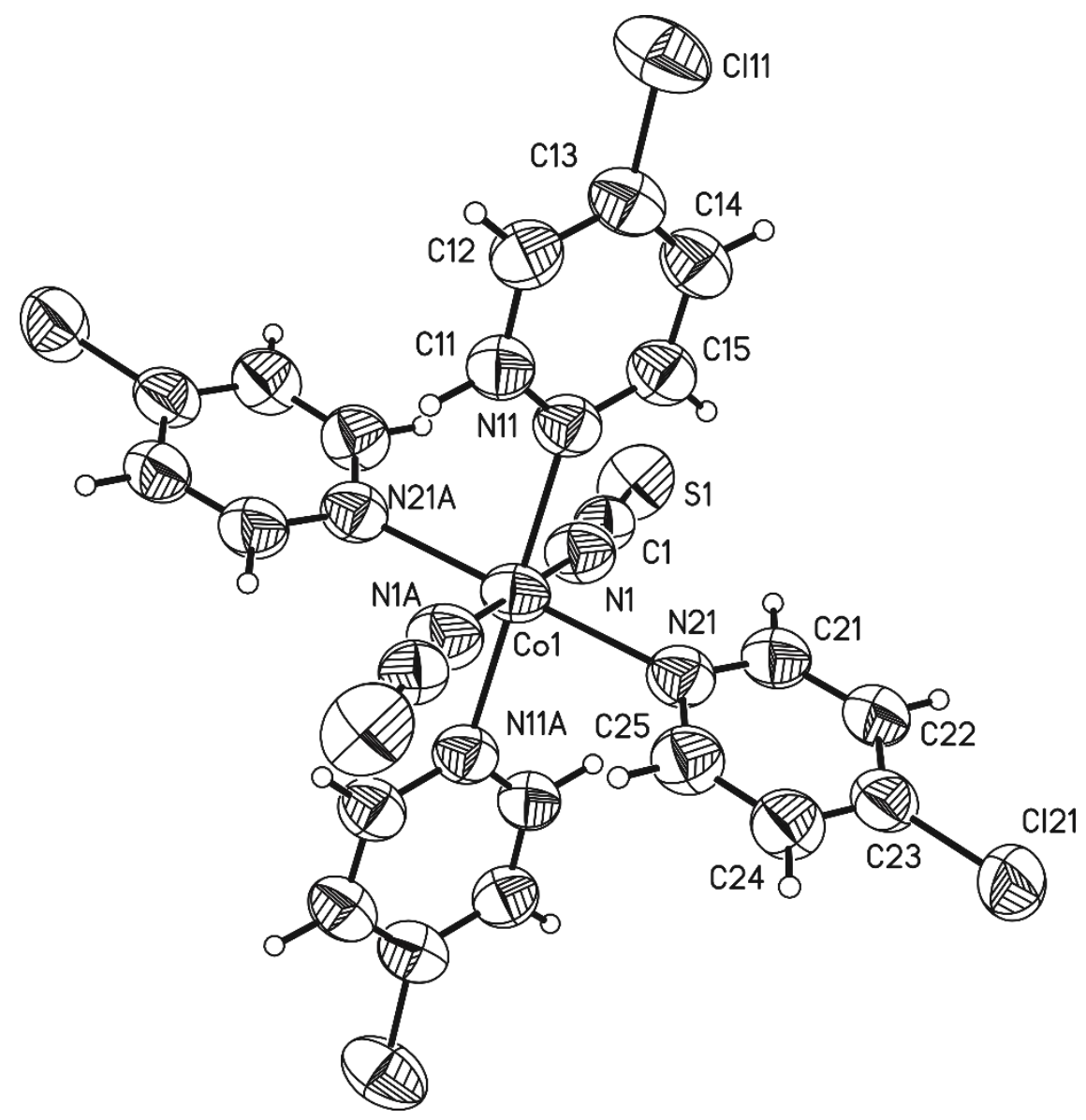

Figure S5. Crystal structure of compound 1 with labeling and displacement ellipsoids drawn at the $50 \%$ probability level. Symmetry code: $A=-x+1,-y,-z$.

Table S2. Selected bond lengths (in Å) and angles (in ${ }^{\circ}$ ) for 1

\begin{tabular}{llll}
\hline \multicolumn{4}{c}{ Co(NCS) ${ }_{2}$ (4-chloropyridine) } \\
\hline Co1-N1A & $2.054(2)$ & Co1-N11A & $2.185(2)$ \\
Co1-N1 & $2.054(2)$ & Co1-N21A & $2.229(2)$ \\
Co1-N11 & $2.185(2)$ & Co1-N21 & $2.229(2)$ \\
& & & \\
N1A-Co1-N1 & $180.0(3)$ & N11-Co1-N21A & $86.57(9)$ \\
N1A-Co1-N11 & $89.81(9)$ & N11A-Co1-N21A & $93.43(9)$ \\
N1-Co1-N11 & $90.19(9)$ & N1A-Co1-N21 & $90.69(10)$ \\
N1A-Co1-N11A & $90.19(9)$ & N1-Co1-N21 & $89.31(10)$ \\
N1-Co1-N11A & $89.81(9)$ & N11-Co1-N21 & $93.43(9)$ \\
N11-Co1-N11A & 180.0 & N11A-Co1-N21 & $86.57(9)$ \\
N1A-Co1-N21A & $89.32(10)$ & N21A-Co1-N21 & 180.0 \\
N1-Co1-N21A & $90.68(10)$ & N11-Co1-N21A & $86.57(9)$ \\
\hline
\end{tabular}




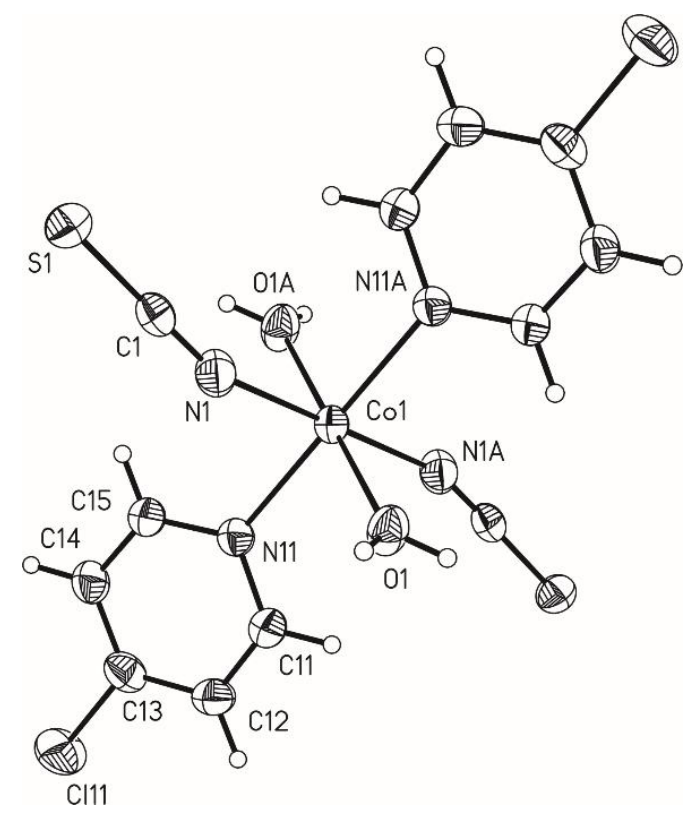

Figure S6. Crystal structure of compound 2 with labeling and displacement ellipsoids drawn at the $50 \%$ probability level. Symmetry code: $A=-x+1,-y+1,-z+1$.

Table S3. Selected bond lengths (in Å) and angles (in ${ }^{\circ}$ ) for 2

\begin{tabular}{|c|c|c|c|}
\hline \multicolumn{4}{|c|}{$\mathrm{Co}(\mathrm{NCS})_{2}$ (4-chloropyridine $)_{2}\left(\mathrm{H}_{2} \mathrm{O}\right)_{2}$} \\
\hline Co1-N1 & $2.0798(13)$ & Co1-01A & $2.0863(10)$ \\
\hline Co1-N1A & $2.0798(13)$ & Co1-N11 & $2.1677(12)$ \\
\hline Co1-01 & $2.0863(10)$ & Co1-N11A & $2.1677(12)$ \\
\hline N1-Co1-N1A & 180.0 & O1A-Co1-N11 & $91.50(5)$ \\
\hline N1-Co1-O1 & $92.42(5)$ & N1-Co1-N11A & $89.99(5)$ \\
\hline N1A-Co1-O1 & $87.58(5)$ & $\mathrm{N} 1 \mathrm{~A}-\mathrm{Co} 1-\mathrm{N} 11 \mathrm{~A}$ & $90.01(5)$ \\
\hline N1-Co1-O1A & $87.58(5)$ & O1-Co1-N11A & $91.50(5)$ \\
\hline N1A-Co1-O1A & $92.42(5)$ & O1A-Co1-N11A & $88.50(5)$ \\
\hline 01-Co1-01A & $180.00(6)$ & N11-Co1-N11A & 180.0 \\
\hline N1-Co1-N11 & $90.01(5)$ & C1-N1-Co1 & $158.66(12)$ \\
\hline N1A-Co1-N11 & $89.99(5)$ & C15-N11-Co1 & $122.03(10)$ \\
\hline O1-Co1-N11 & $88.50(5)$ & $\mathrm{C} 11-\mathrm{N} 11-\mathrm{Co} 1$ & $120.83(10)$ \\
\hline
\end{tabular}




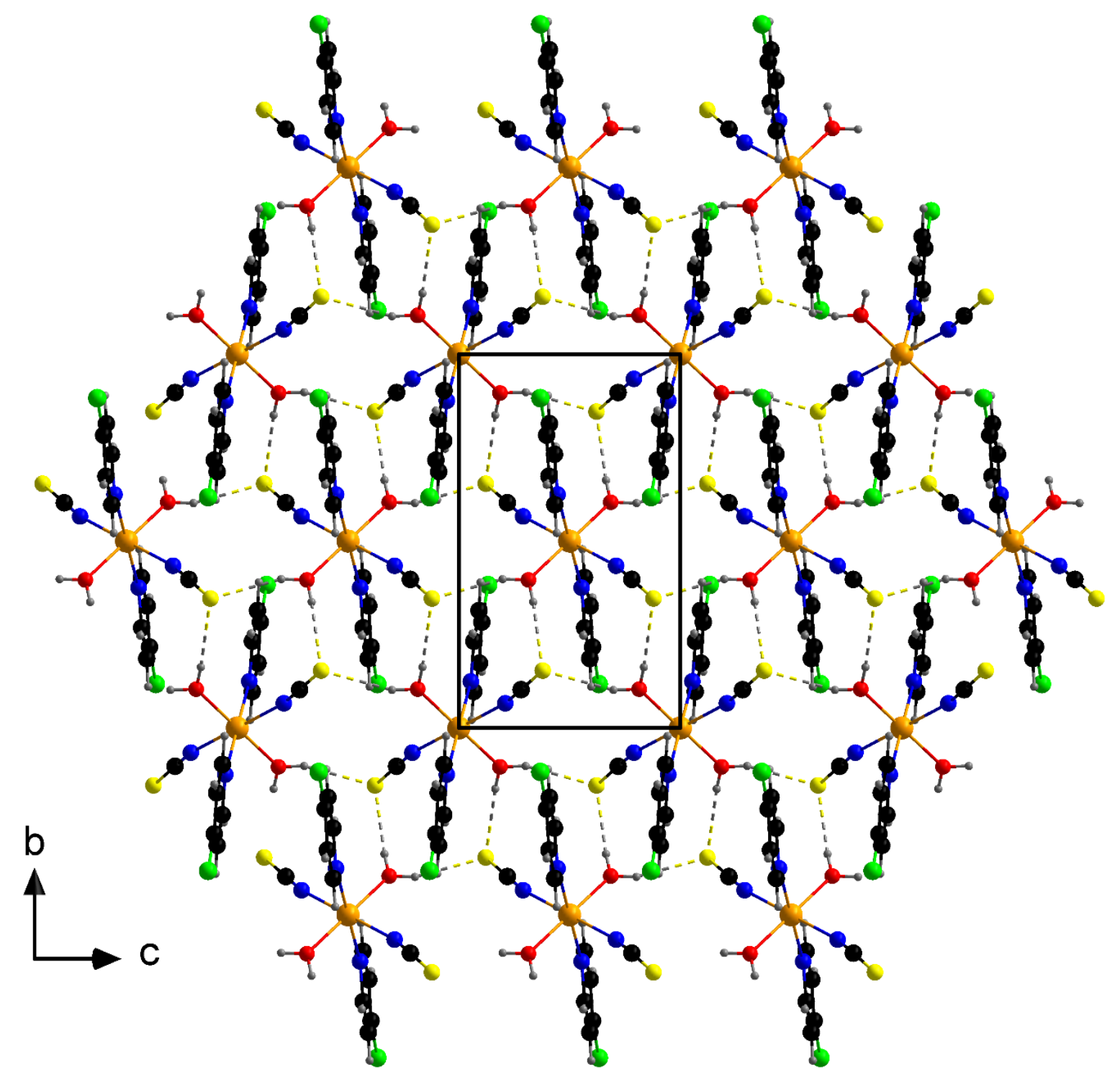

Figure S7. Part of the crystal structure of compound $\mathbf{2}$ with view along the $\boldsymbol{a}$-axis onto a layer formed by intermolecular hydrogen bonding, which is shown as dashed lines. 


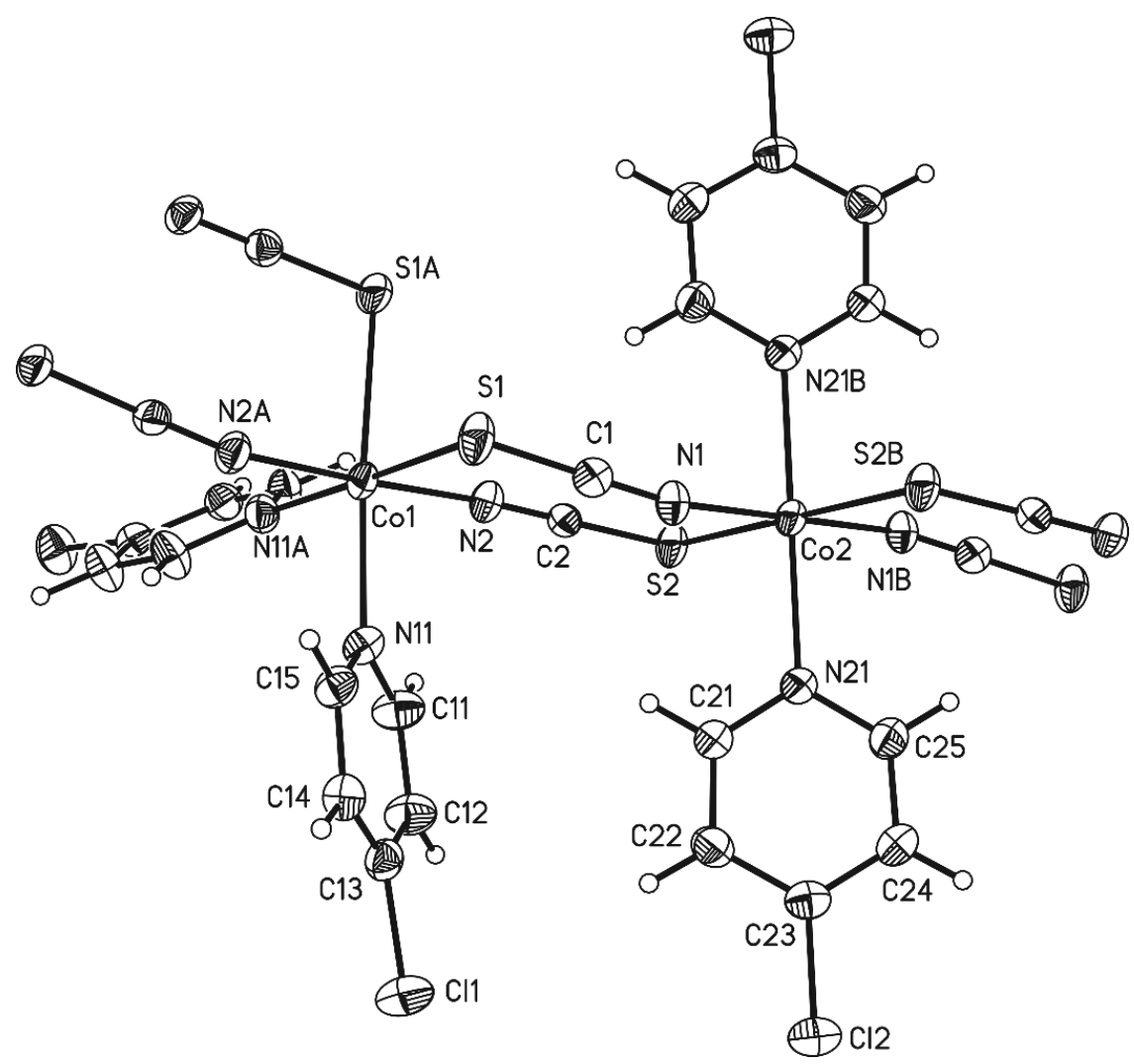

Figure 58. Crystal structure of compound $\mathbf{3 C}$ with labeling and displacement ellipsoids drawn at the $50 \%$ probability level. Symmetry code: $A=-x, y,-z+1 / 2, B=-x+1 / 2,-y+1 / 2,-z+1$.

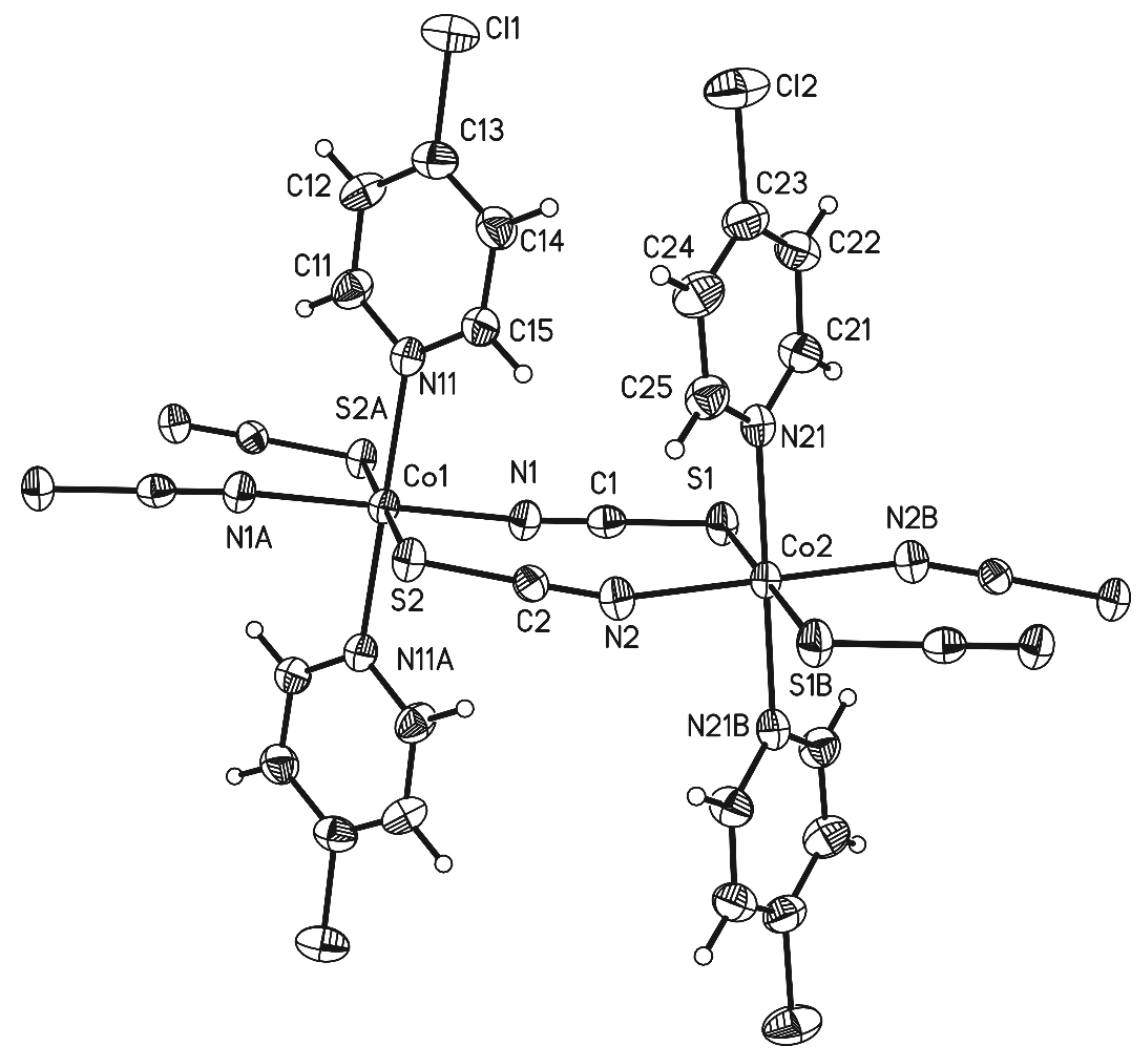

Figure S9. Crystal structure of compound 3L with labeling and displacement ellipsoids drawn at the $50 \%$ probability level. Symmetry code: $A=-x+1,-y+1,-z+1, B=-x+2,-y,-z+1$. 
Table S4. Selected bond lengths (in $\AA$ ) and angles (in ${ }^{\circ}$ ) for $\mathbf{3 C}$ and $\mathbf{3 L}$

\begin{tabular}{|c|c|c|c|}
\hline \multicolumn{4}{|c|}{$\mathrm{Co}(\mathrm{NCS})_{2}$ (4-chloropyridine $)_{2}(3 \mathrm{C})$} \\
\hline Co1-N2A & $2.062(2)$ & Co2-N1 & $2.054(2)$ \\
\hline Co1-N2 & $2.062(2)$ & Co2-N1B & $2.054(2)$ \\
\hline Co1-N11 & $2.170(2)$ & Co2-N21 & $2.205(2)$ \\
\hline Co1-N11A & $2.170(2)$ & Co2-N21B & $2.205(2)$ \\
\hline Co1-S1A & $2.6010(8)$ & $\mathrm{Co} 2-\mathrm{S} 2$ & $2.5628(7)$ \\
\hline Co1-S1 & $2.6010(8)$ & $\mathrm{Co} 2-\mathrm{S} 2 \mathrm{~B}$ & $2.5628(7)$ \\
\hline N2A-Co1-N2 & $177.59(14)$ & $\mathrm{N} 1-\mathrm{Co} 2-\mathrm{N} 1 \mathrm{~B}$ & $180.00(13)$ \\
\hline N2A-Co1-N11 & $92.02(9)$ & N1-Co2-N21 & $90.81(9)$ \\
\hline N2-Co1-N11 & $89.70(9)$ & $\mathrm{N} 1 \mathrm{~B}-\mathrm{Co} 2-\mathrm{N} 21$ & $89.19(9)$ \\
\hline N2A-Co1-N11A & $89.70(9)$ & N1-Co2-N21B & $89.19(9)$ \\
\hline N2-Co1-N11A & $92.02(9)$ & N1B-Co2-N21B & $90.81(9)$ \\
\hline N11-Co1-N11A & $88.67(12)$ & N21-Co2-N21B & 180.0 \\
\hline N2A-Co1-S1A & $93.82(7)$ & $\mathrm{N} 1-\mathrm{Co} 2-\mathrm{S} 2$ & $93.96(7)$ \\
\hline N2-Co1-S1A & $84.50(7)$ & N1B-Co2-S2 & $86.04(7)$ \\
\hline N11-Co1-S1A & $174.03(6)$ & N21-Co2-S2 & $90.29(6)$ \\
\hline N11A-Co1-S1A & $90.12(6)$ & N21B-Co2-S2 & $89.71(6)$ \\
\hline $\mathrm{N} 2 \mathrm{~A}-\mathrm{Co} 1-\mathrm{S} 1$ & $84.50(7)$ & N1-Co2-S2B & $86.04(7)$ \\
\hline N2-Co1-S1 & $93.82(7)$ & $\mathrm{N} 1 \mathrm{~B}-\mathrm{Co} 2-\mathrm{S} 2 \mathrm{~B}$ & $93.96(7)$ \\
\hline N11-Co1-S1 & $90.12(6)$ & N21-Co2-S2B & $89.71(6)$ \\
\hline N11A-Co1-S1 & $174.03(6)$ & N21B-Co2-S2B & $90.29(6)$ \\
\hline S1A-Co1-S1 & $91.68(4)$ & $\mathrm{S} 2-\mathrm{Co} 2-\mathrm{S} 2 \mathrm{~B}$ & 180.0 \\
\hline \multicolumn{4}{|c|}{$\mathrm{Co}(\mathrm{NCS})_{2}$ (4-chloropyridine) $)_{2}(3 \mathrm{~L})$} \\
\hline Co1-N1A & $2.051(3)$ & $\mathrm{Co} 2-\mathrm{N} 2 \mathrm{~B}$ & $2.075(3)$ \\
\hline Co1-N1 & $2.051(3)$ & $\mathrm{Co} 2-\mathrm{N} 2$ & $2.075(3)$ \\
\hline Co1-N11A & $2.171(3)$ & Co2-N21B & $2.160(3)$ \\
\hline Co1-N11 & $2.171(3)$ & Co2-N21 & $2.160(3)$ \\
\hline Co1-S2 & $2.6254(11)$ & Co2-S1 & $2.5918(11)$ \\
\hline Co1-S2A & $2.6254(11)$ & Co2-S1B & $2.5918(11)$ \\
\hline N1A-Co1-N1 & 180.0 & $\mathrm{~N} 2 \mathrm{~B}-\mathrm{Co} 2-\mathrm{N} 2$ & 180.0 \\
\hline N1A-Co1-N11A & $89.42(13)$ & N2B-Co2-N21B & $88.70(13)$ \\
\hline N1-Co1-N11A & $90.59(13)$ & N2-Co2-N21B & $91.30(13)$ \\
\hline N1A-Co1-N11 & $90.58(13)$ & $\mathrm{N} 2 \mathrm{~B}-\mathrm{Co} 2-\mathrm{N} 21$ & $91.30(13)$ \\
\hline N1-Co1-N11 & $89.42(13)$ & N2-Co2-N21 & $88.70(13)$ \\
\hline N11A-Co1-N11 & 180.0 & N21B-Co2-N21 & $180.00(17)$ \\
\hline N1A-Co1-S2 & $88.00(10)$ & $\mathrm{N} 2 \mathrm{~B}-\mathrm{Co} 2-\mathrm{S} 1$ & $86.21(10)$ \\
\hline N1-Co1-S2 & $92.00(10)$ & $\mathrm{N} 2-\mathrm{Co} 2-\mathrm{S} 1$ & $93.79(10)$ \\
\hline N11A-Co1-S2 & $89.67(9)$ & N21B-Co2-S1 & $90.21(10)$ \\
\hline N11-Co1-S2 & $90.33(9)$ & N21-Co2-S1 & $89.79(10)$ \\
\hline N1A-Co1-S2A & $92.00(10)$ & $\mathrm{N} 2 \mathrm{~B}-\mathrm{Co} 2-\mathrm{S} 1 \mathrm{~B}$ & $93.79(10)$ \\
\hline N1-Co1-S2A & $88.00(10)$ & N2-Co2-S1B & $86.21(10)$ \\
\hline N11A-Co1-S2A & $90.33(9)$ & N21B-Co2-S1B & $89.79(10)$ \\
\hline N11-Co1-S2A & $89.67(9)$ & N21-Co2-S1B & $90.21(10)$ \\
\hline$S 2-C 01-S 2 A$ & 180.0 & S1-Co2-S1B & 180.0 \\
\hline
\end{tabular}



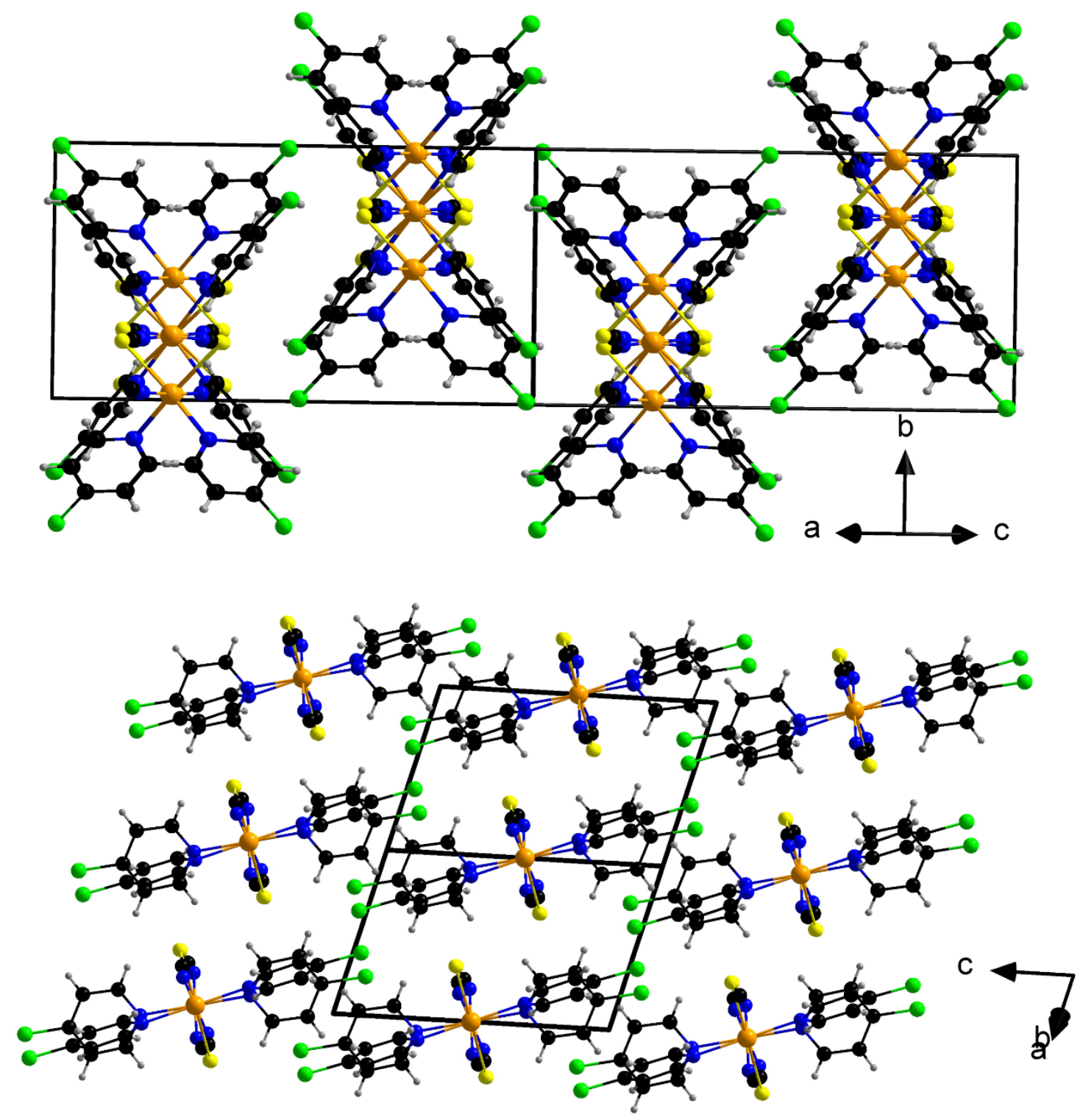

Figure S10. Arrangement of the chains in the crystal structure of $\mathbf{3 C}$ (top) and 3L (bottom). 


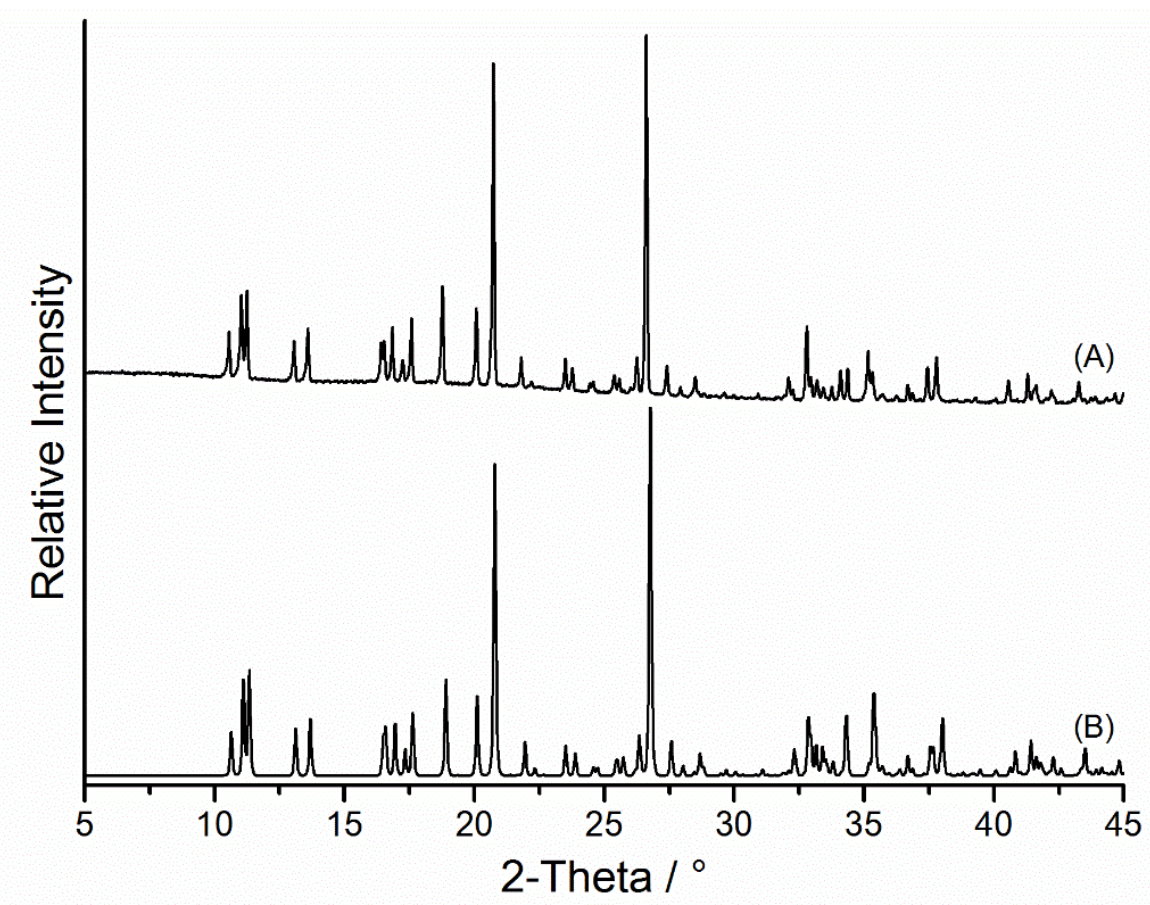

Figure S11. Experimental (A) and calculated (B) XRPD pattern of 3C.

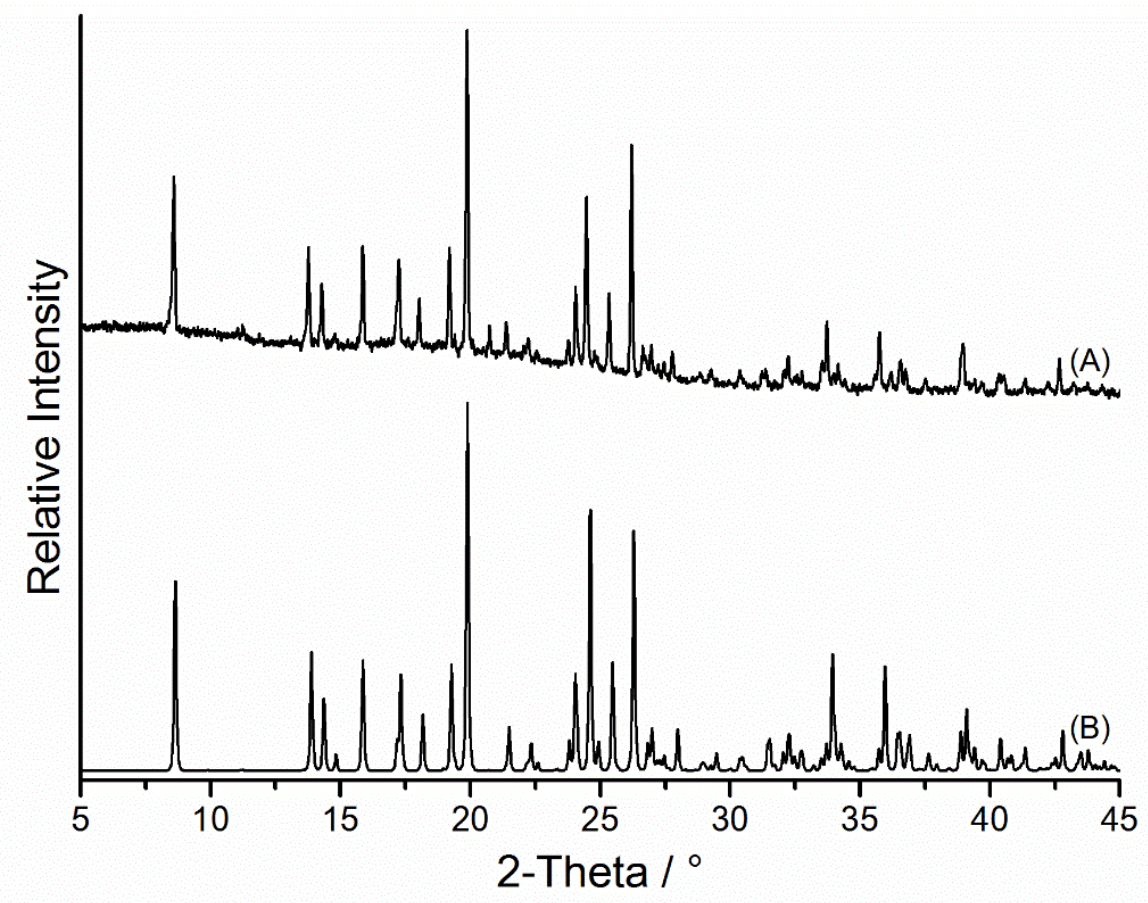

Figure S12. Experimental (A) and calculated (B) XRPD pattern of 3L obtained from solution. 


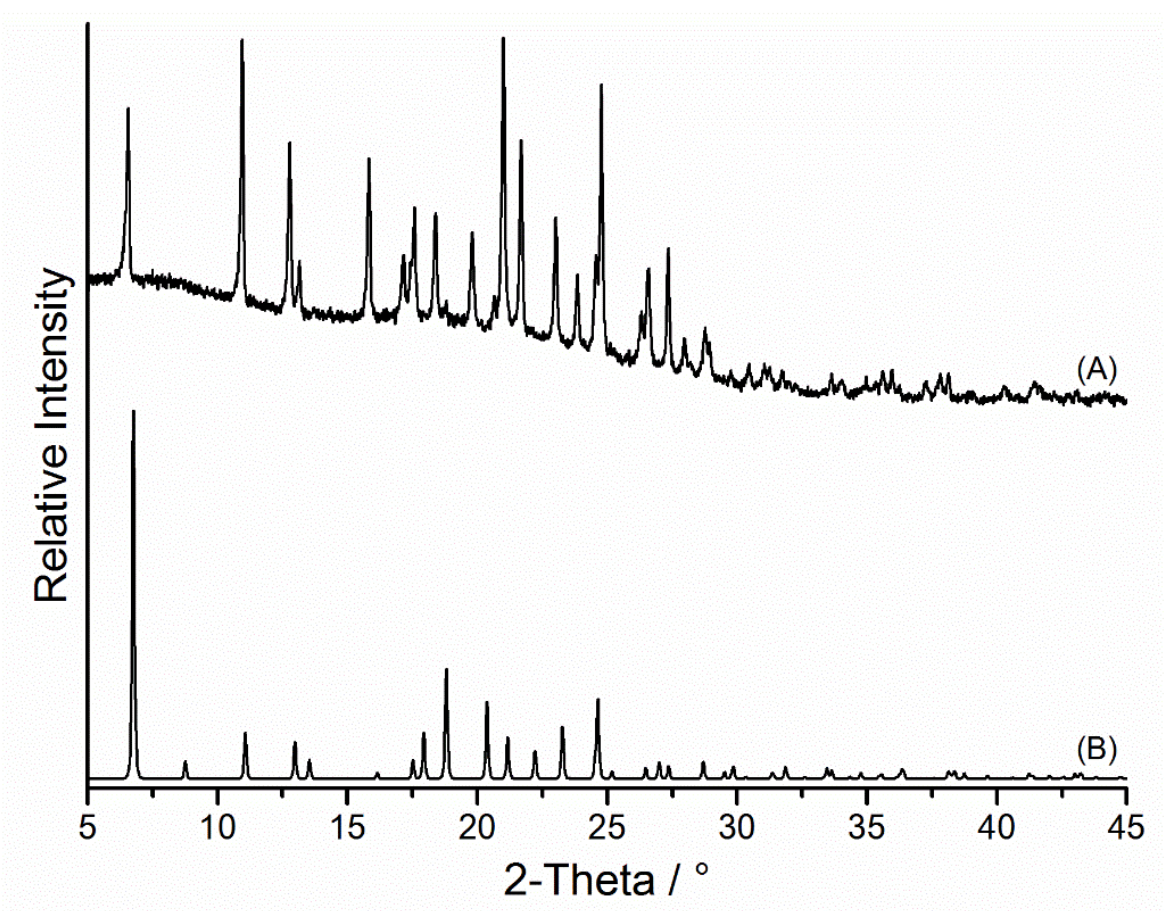

Figure S13. Experimental (A) and calculated (B) XRPD pattern of 1 obtained from solution. Please note, that the pattern is affected by strong texture.

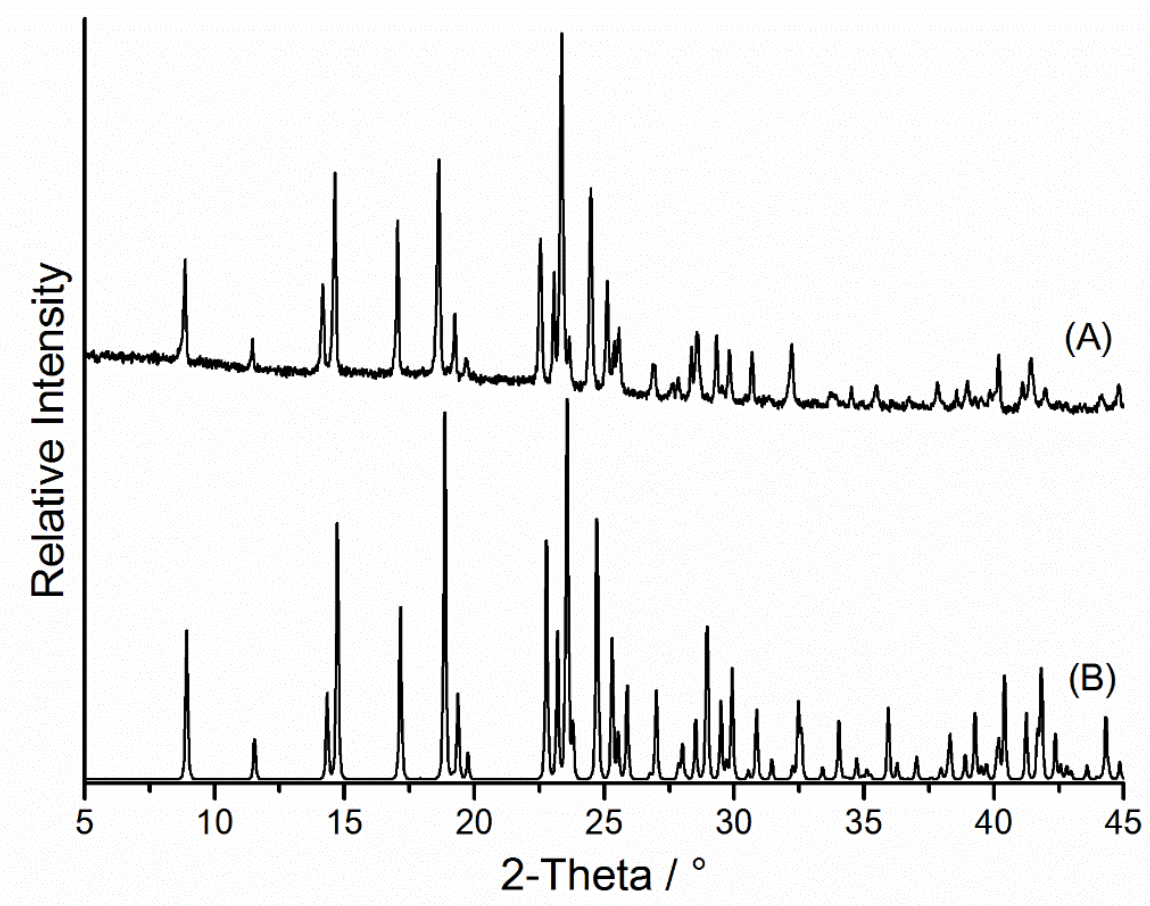

Figure S14. Experimental (A) and calculated (B) XRPD pattern of 2. 

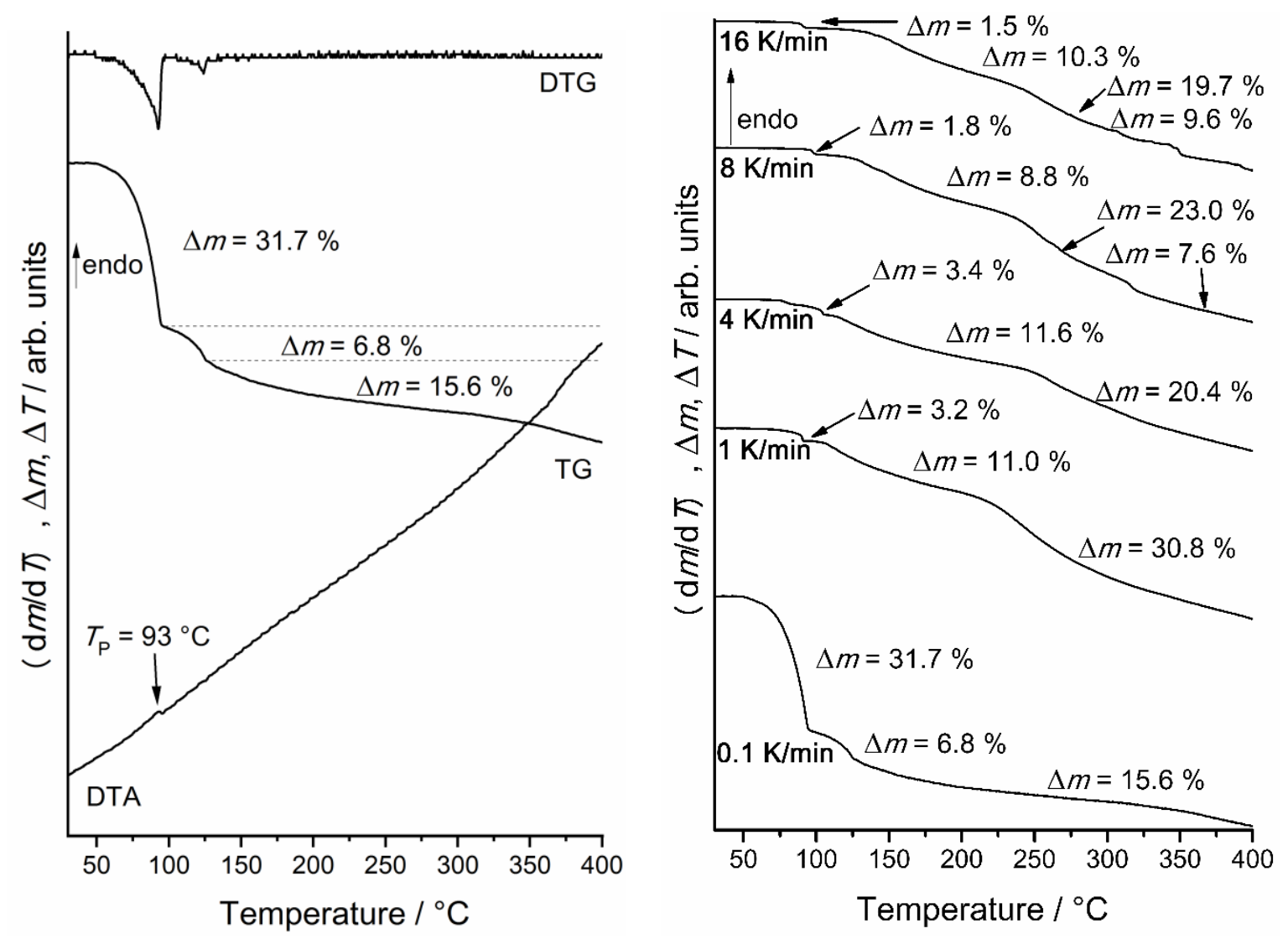

Figure S15. DTA, TG, and DTG curves as well as heating rate dependent measurements for 1.

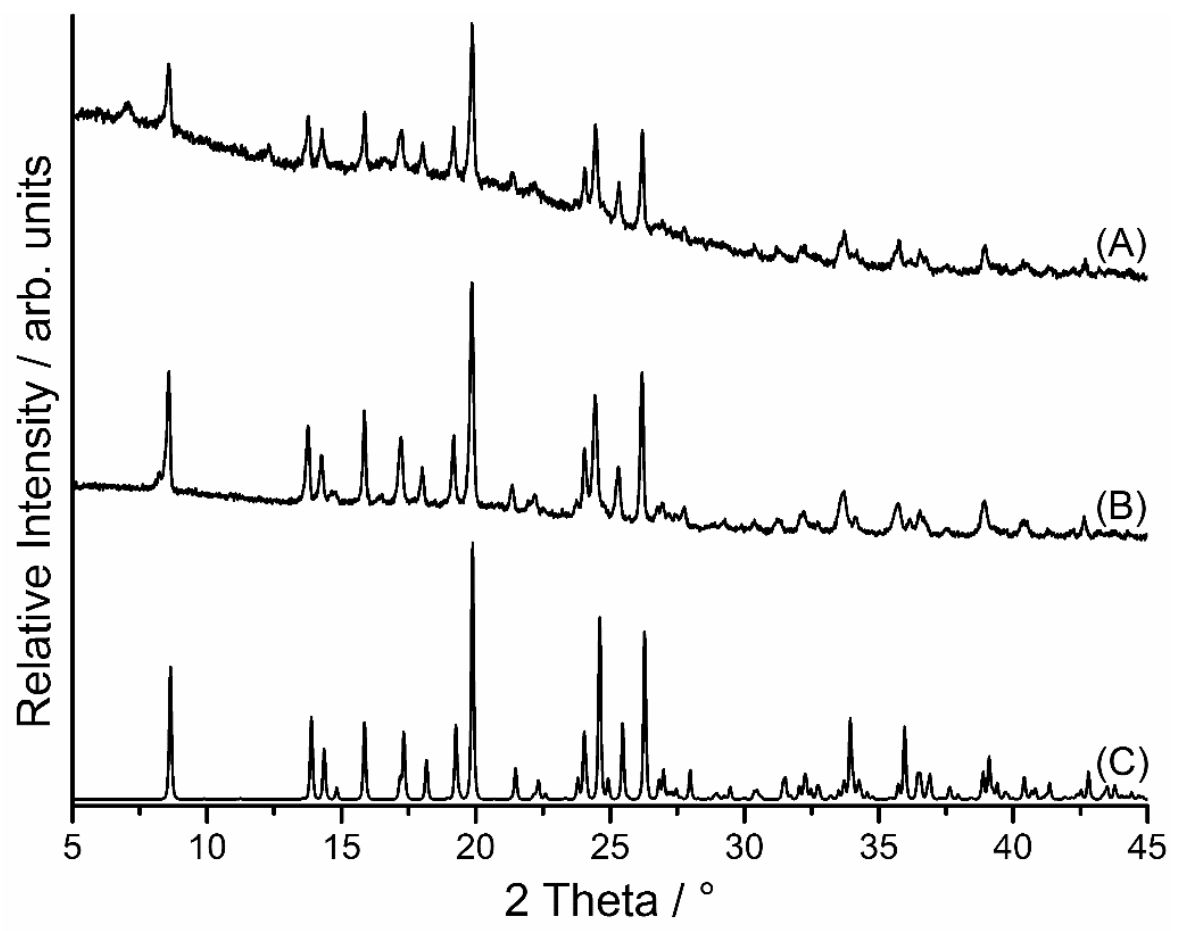

Figure S16. Experimental XRPD pattern of the residue obtained by thermogravimetric measurements of $\mathbf{1}(\mathrm{A})$ and $\mathbf{2}$ (B) together with the calculated pattern of $\mathbf{3 L}(\mathrm{C})$. 

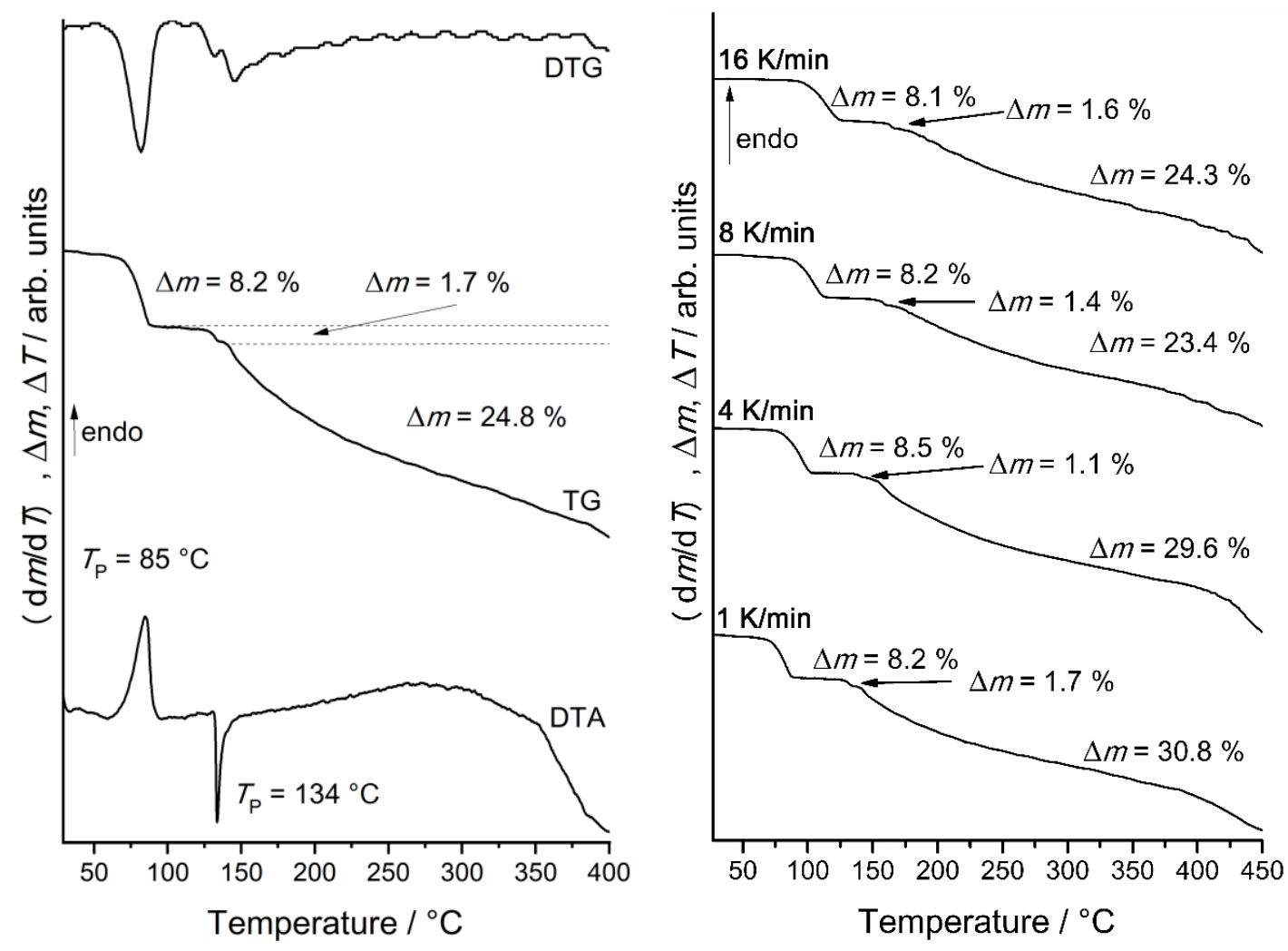

Figure S17. DTA, TG, and DTG curves with a heating rate of $1{ }^{\circ} \mathrm{C} / \mathrm{min}$ (left) as well as heating rate dependent measurements for $\mathbf{2}$ (right).

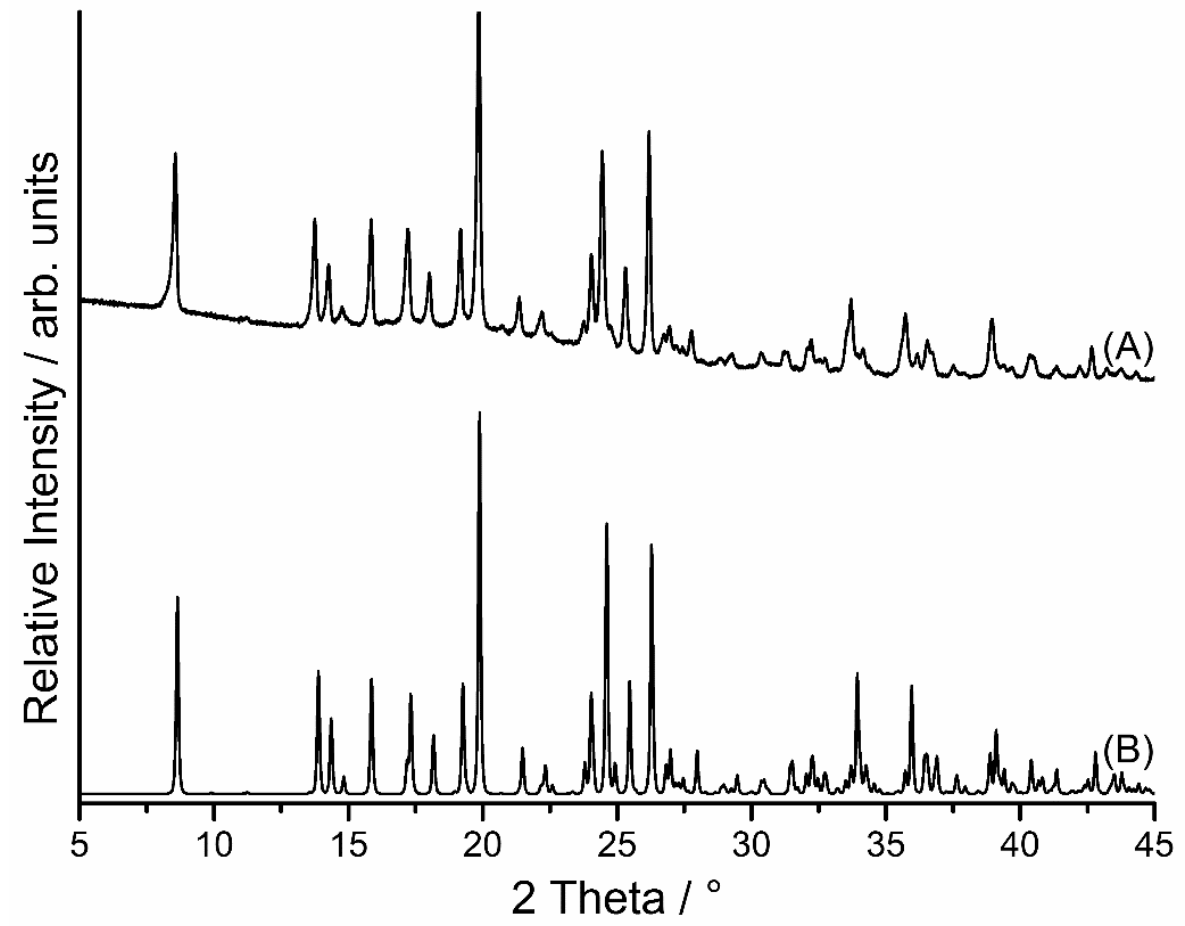

Figure S18. Experimental XRPD pattern of the residue obtained by annealing of $\mathbf{2}$ (A) and calculated XRPD pattern of 3L (B). 


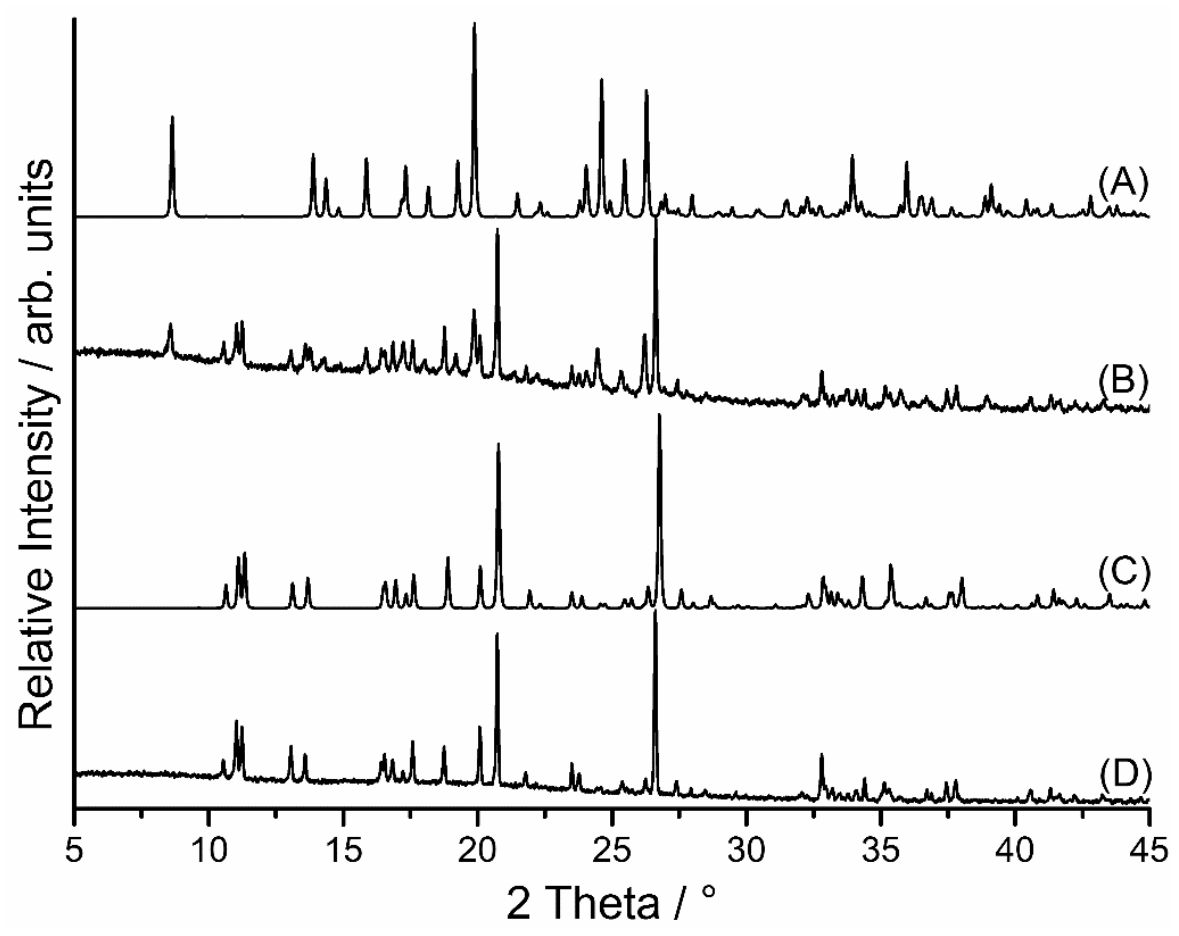

Figure S19. Calculated XRPD pattern of $\mathbf{3 L}(\mathrm{A})$ and $\mathbf{3 C}(\mathrm{C})$ together with the experimental pattern of a mixture of both isomers (B) and after stirring this mixture in methanol for five days (D).

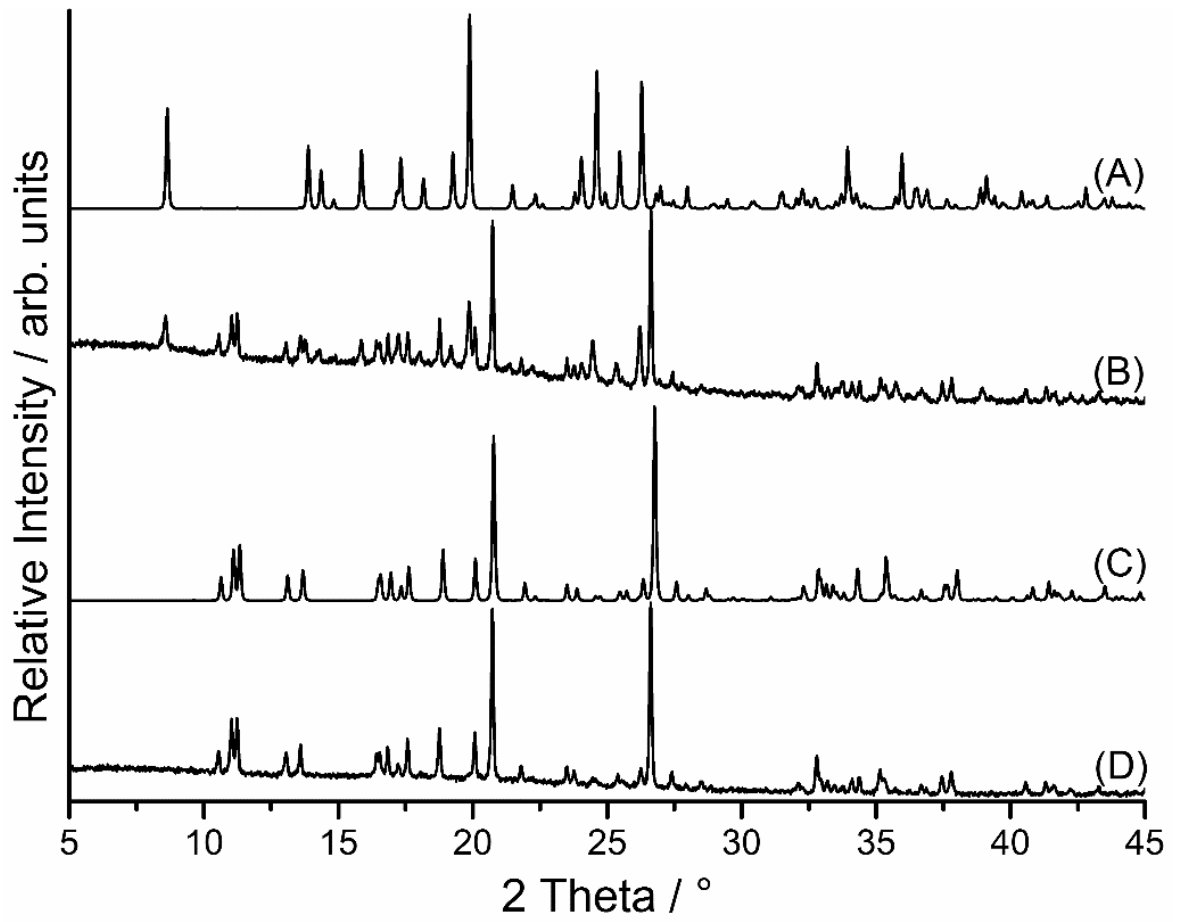

Figure S20. Calculated XRPD pattern of 3L (A) and $\mathbf{3 C}(\mathrm{C})$ together with the experimental pattern of a mixture of both isomers (B) and after stirring this mixture in ethanol for five days (D). 

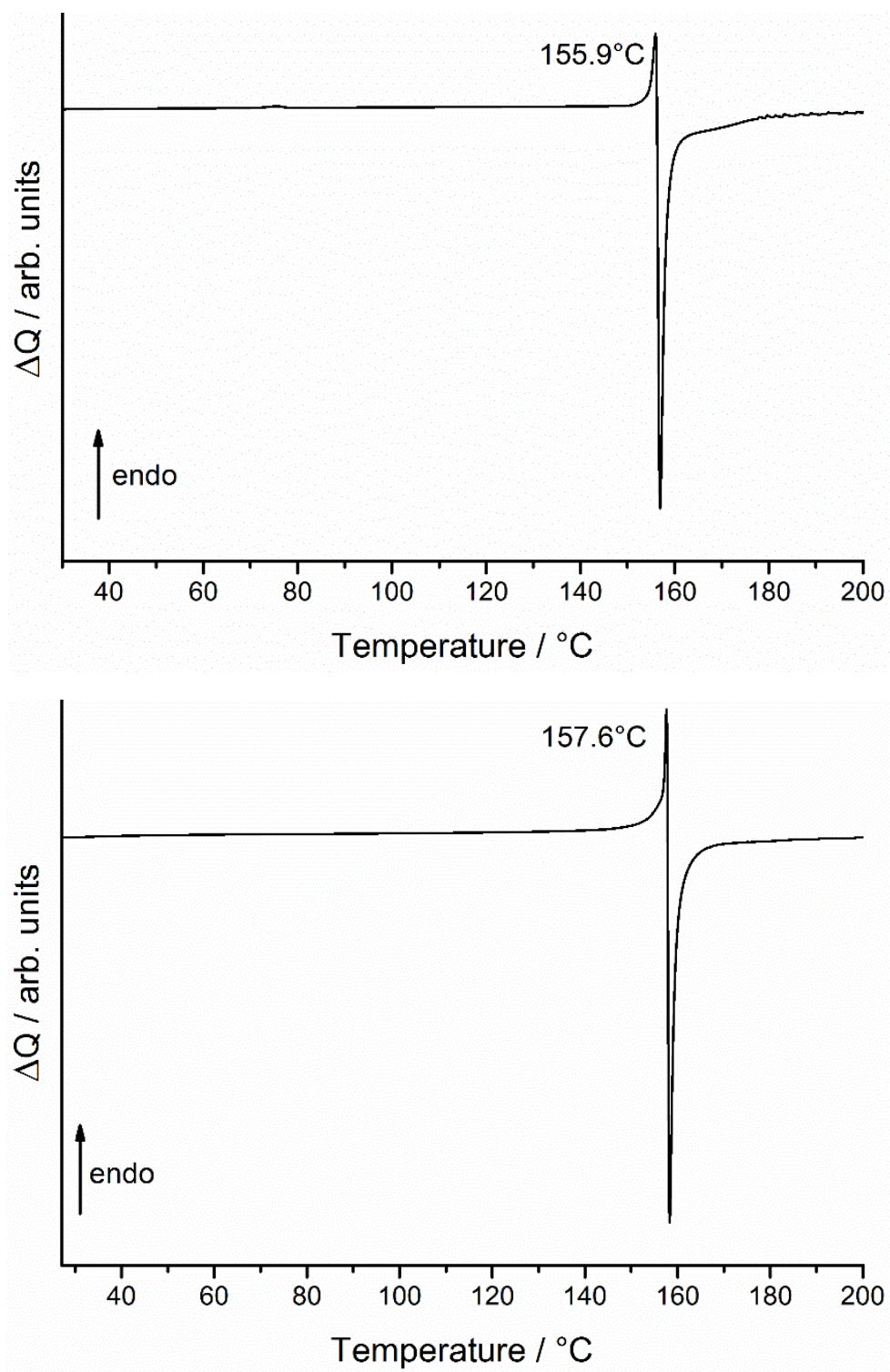

Figure S21. DSC curve of $\mathbf{3 C}$ (top) and $\mathbf{3 L}$ (bottom) at $10^{\circ} \mathrm{C} / \mathrm{min}$. 


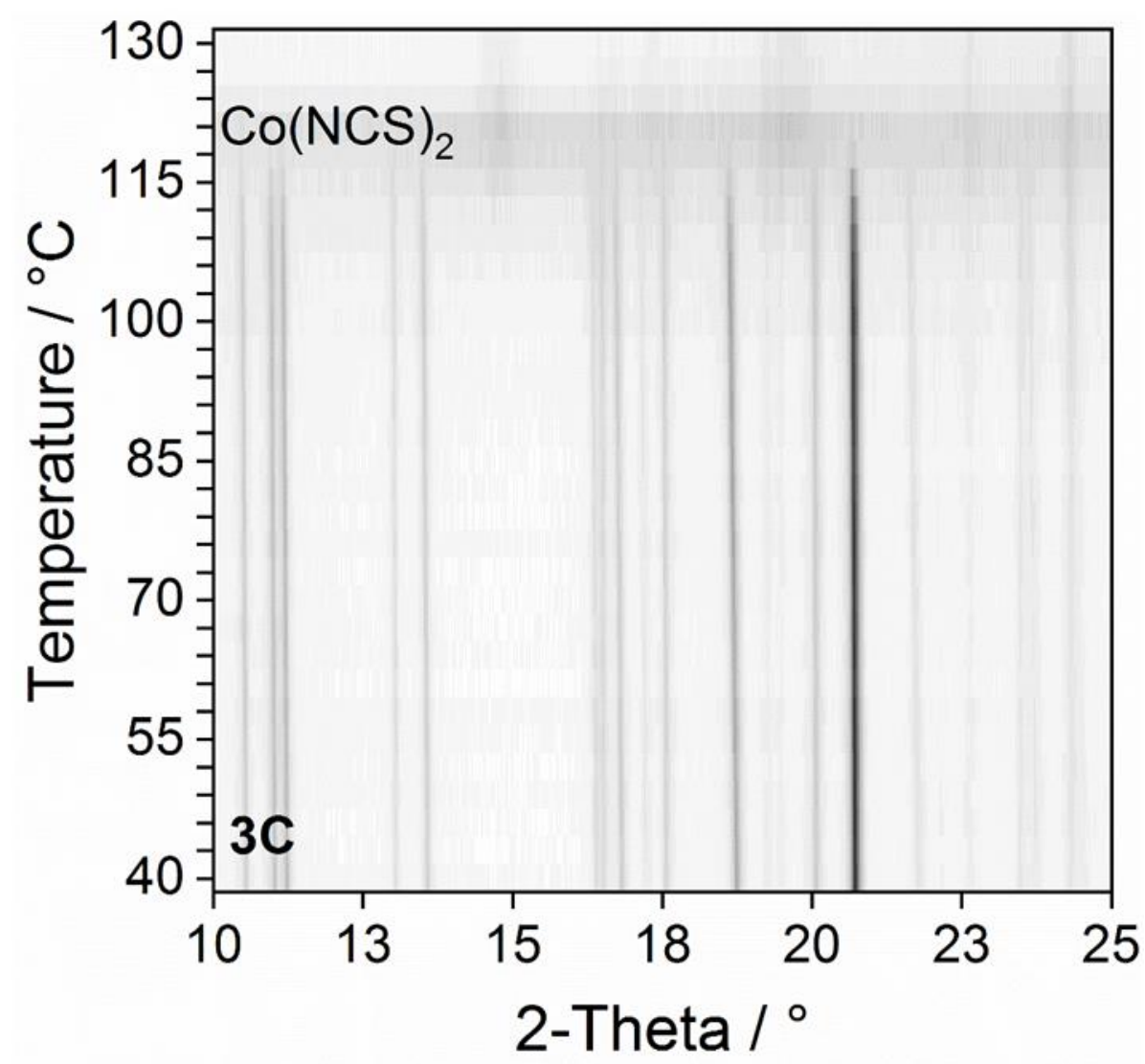

Figure S22. Temperature dependent XRPD measurements of 3C.

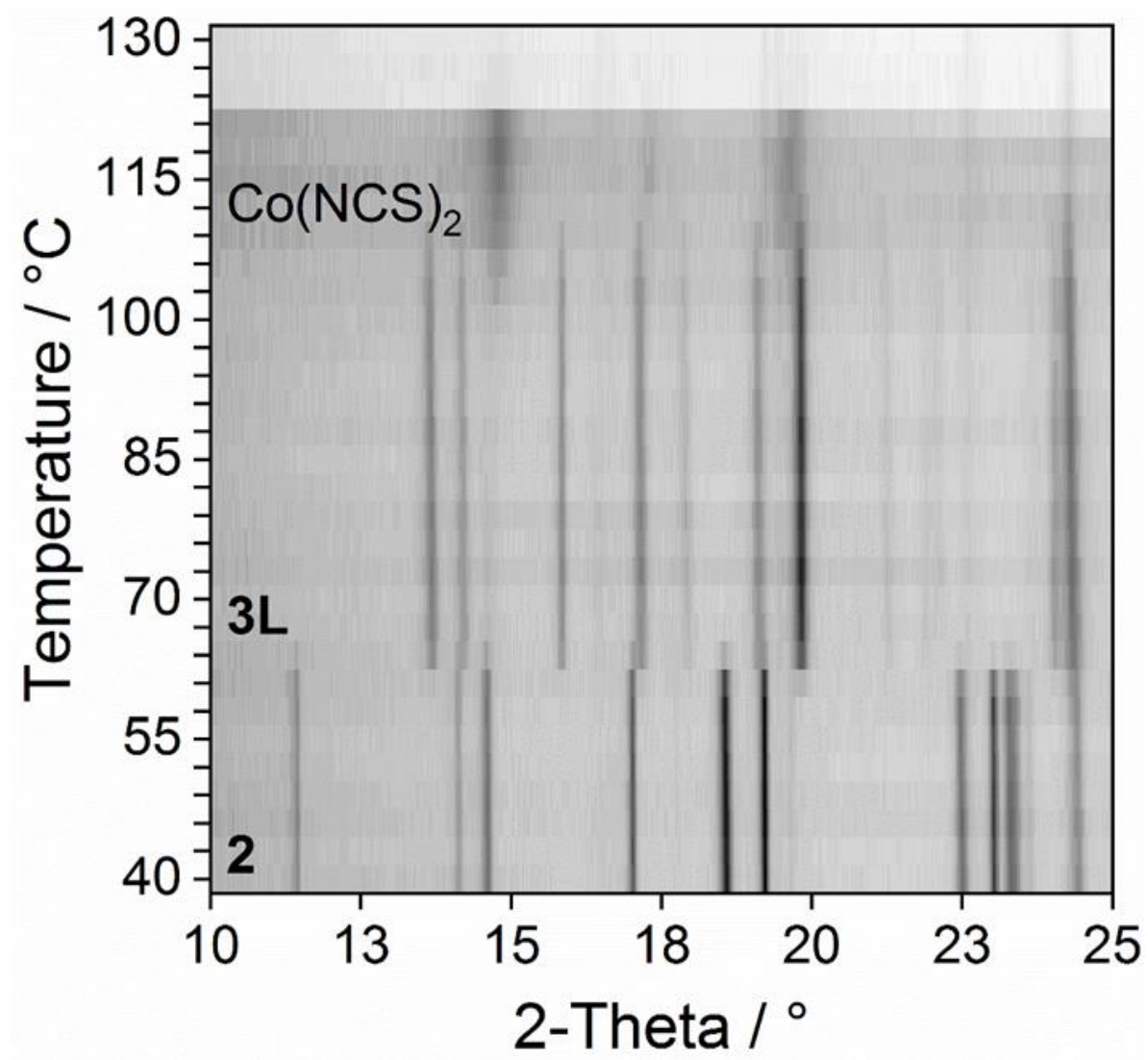

Figure S23. Temperature dependent XRPD measurements of compound $\mathbf{2}$. 


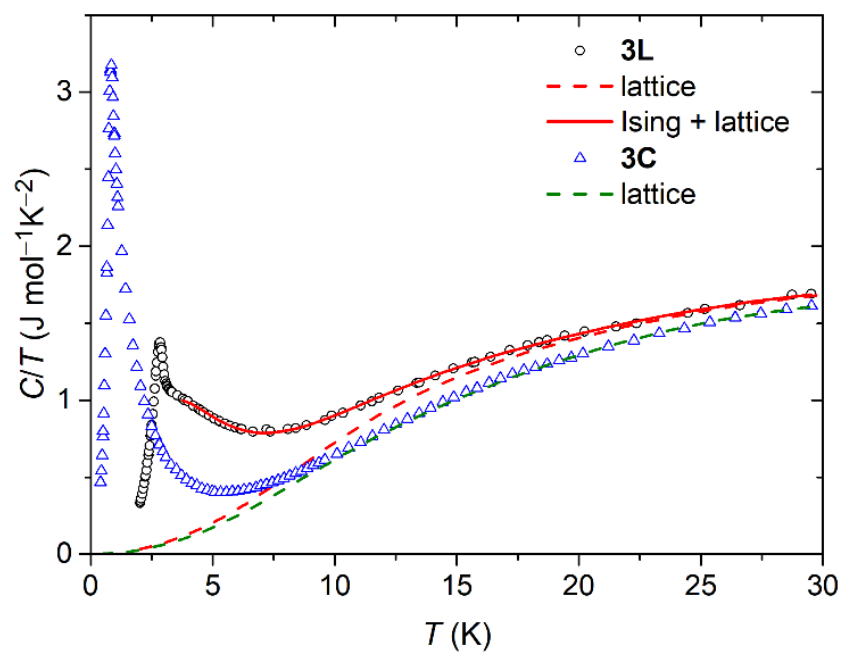

Figure S24. Temperature dependence of the specific heat $C$, measured for $\mathbf{3 C}$ and $\mathbf{3 L}$ and shown as $C / T$. Solid lines are fitted as a sum of lattice and spin contributions. The lattice contributions are marked with dashed lines, while the sum is marked with solid lines.

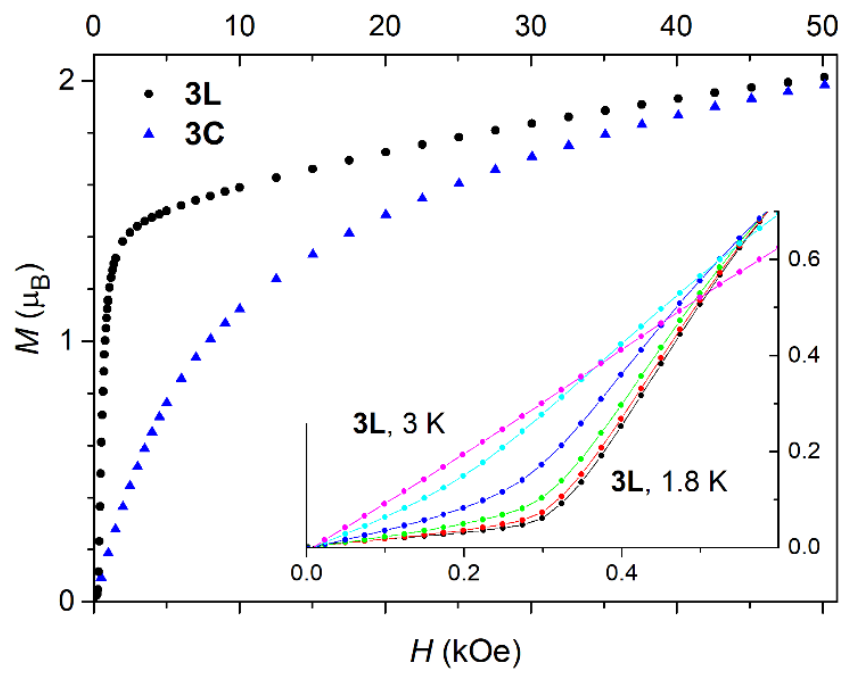

Figure S25. Magnetization of $\mathbf{3 C}$ (triangles) and $\mathbf{3 L}$ (dots) measured at $1.8 \mathrm{~K}$. Inset: Low field magnetization of $\mathbf{3 L}$ at different temperatures from 1.8 to $3 \mathrm{~K}$, showing the metamagnetic transition. Lines are to guide the eye. 


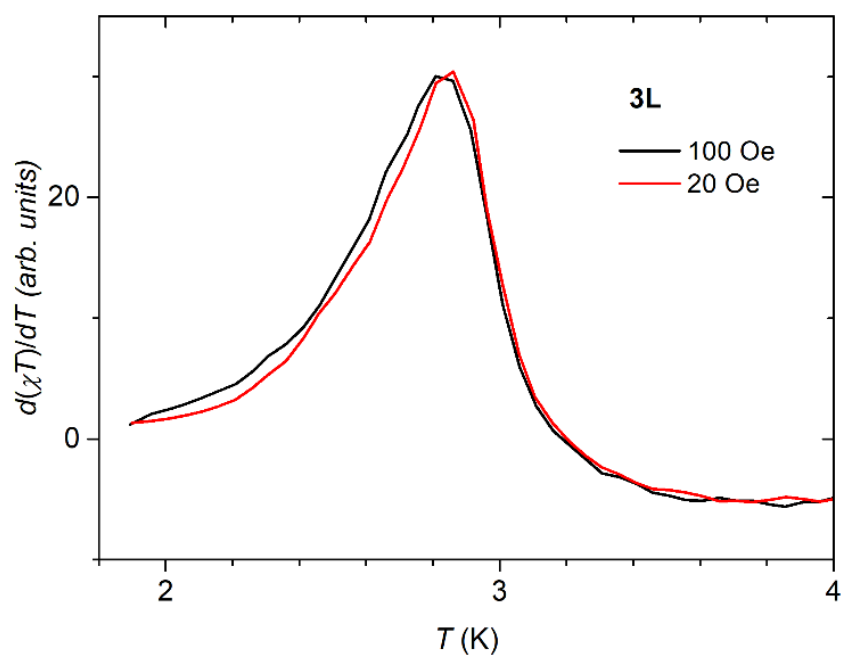

Figure S26. The derivative of low-field susceptibility, as used to determine the critical temperature of the antiferromagnetic phase of $\mathbf{3 L}$.

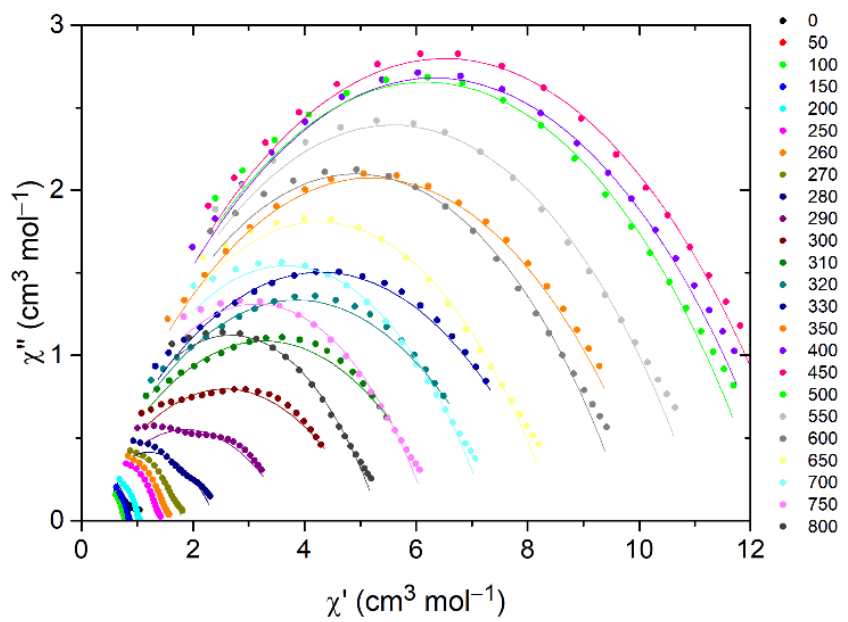

Figure S27. Ac magnetic susceptibility measured for $\mathbf{3 L}$ at $2 \mathrm{~K}$ and different applied dc fields (values given in Oe), shown in Argand plot. The solid lines are fitted using a single mode Cole-Cole model. 


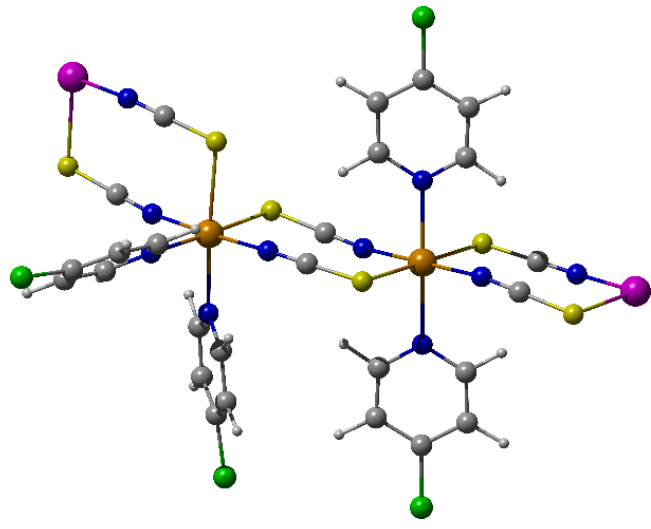

3C-Co1Co2

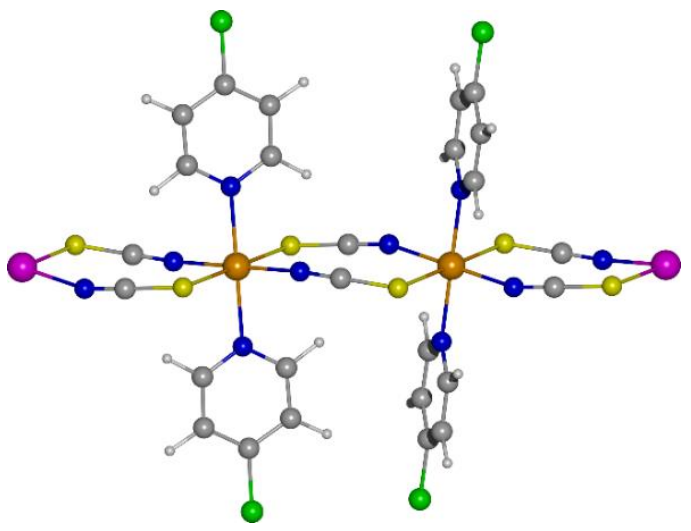

3L-Co1Co2

Figure S28. Dinuclear structural models $\left[\mathrm{Co}_{2} \mathrm{Zn}_{2}(\mathrm{NCS})_{6}(4 \text {-chloropyridine })_{4}\right]^{2+}$ used in the BS-DFT calculations for $3 \mathrm{C}$ (3C-Co1Co2; left) and $3 \mathrm{~L}$ (3L-Co1Co2; right). The pink spheres designate zinc(II) ions to compensate the negative charge of the structural models.

Table S5. BS-DFT results for the Heisenberg coupling constants $\left(J_{B S}\right)$

\begin{tabular}{lcrrrcc}
\hline Computational model & State & $2 S+1$ & $E_{\text {rel }}$ (Hartree) & \multicolumn{1}{c}{$\left\langle\widehat{S}^{2}\right\rangle$} & $\Delta E\left(\mathrm{~cm}^{-1}\right)$ & $J_{\mathrm{BS}}\left(\mathrm{cm}^{-1}\right)$ \\
\hline 3C-Co1Co2 & HS & 7 & -12098.445033 & 12.050 & 24.4 & 4.1 \\
& BS & 1 & -12098.444922 & 3.048 & & \\
\hline 3L-Co1Co2 & HS & 7 & -12098.439272 & 12.066 & 18.4 & 3.1 \\
& BS & 1 & -12098.439187 & 3.059 & & \\
\hline
\end{tabular}




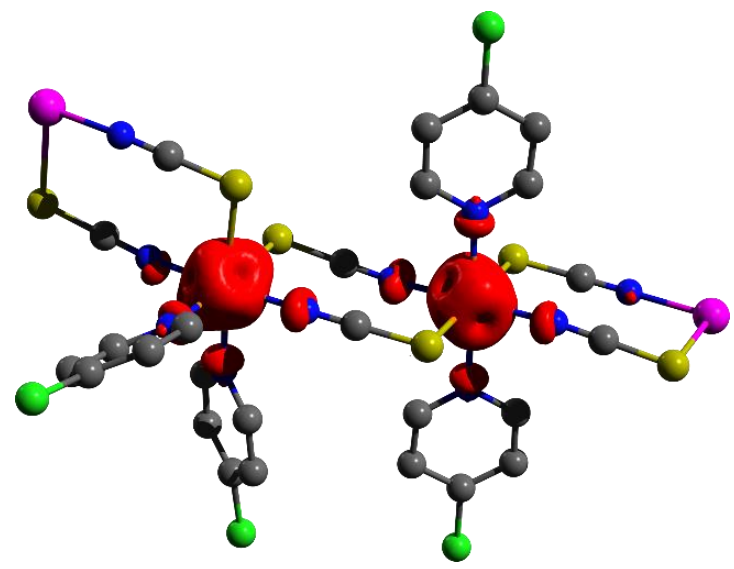

3C-Co1Co2 (HS)

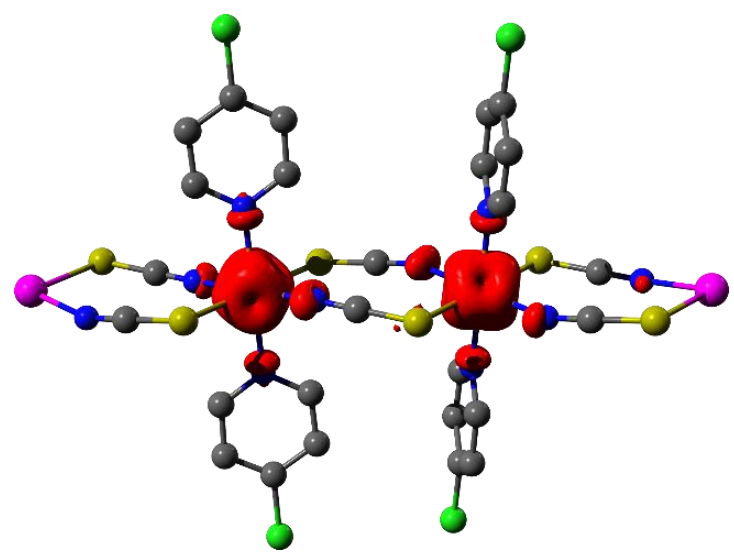

3L-Co1Co2 (HS)

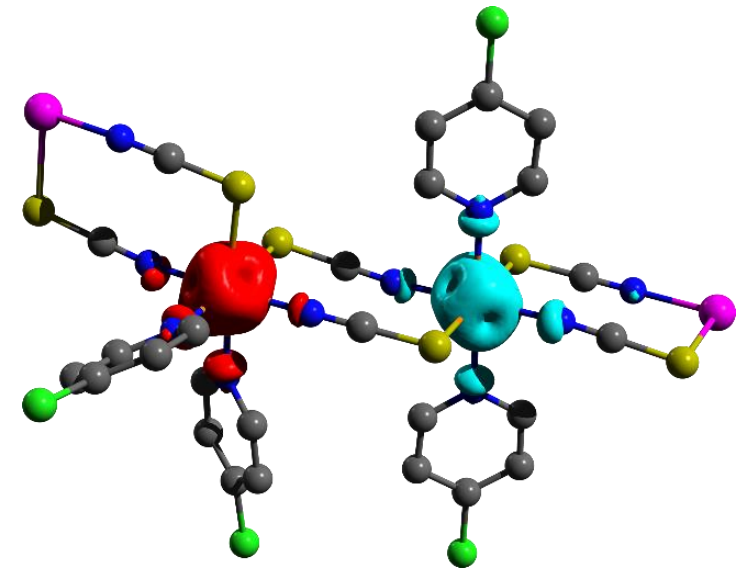

3C-Co1Co2 (BS)

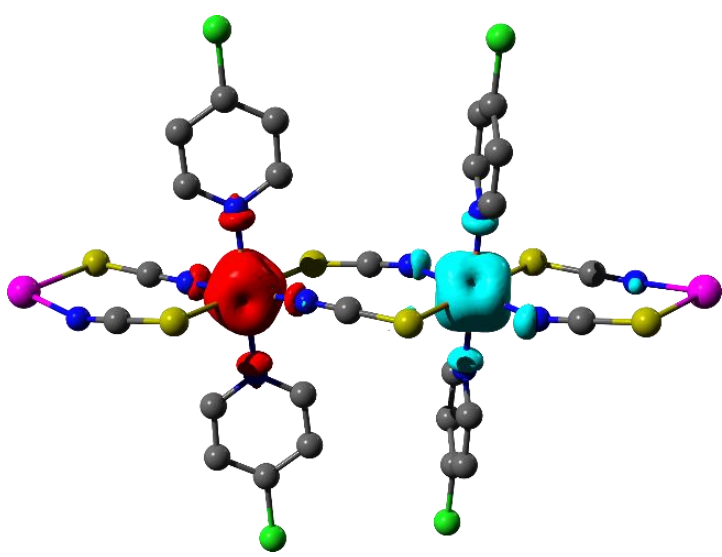

3L-Co1Co2 (BS)

Figure S29. Spin densities obtained from BS-DFT (iso-value 0.005) for 3C (first row) and 3L (second row) for the high-spin state (HS; left column) and broken-symmetry state (BS; right column). Red (cyan) isosurfaces represent net $\alpha(\beta)$ spin densities.
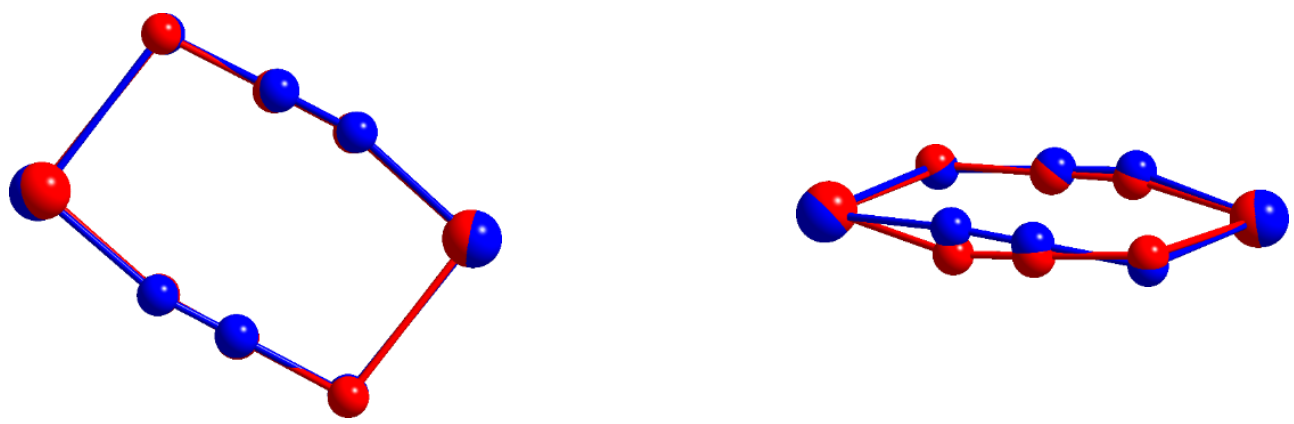

Figure S30. Overlay of the $\left[\mathrm{CO}_{2}(\mathrm{NCS})_{2}\right]^{2+}$ cores as found in $\mathbf{3 C}$ (red) and $\mathbf{3 L}$ (blue) from two different perspectives. The (NCS) ${ }_{2}$ bridges mediate the magnetic exchange between the cobalt(II) ions. 


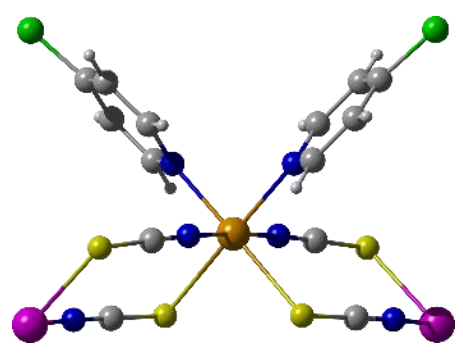

3C-Co1

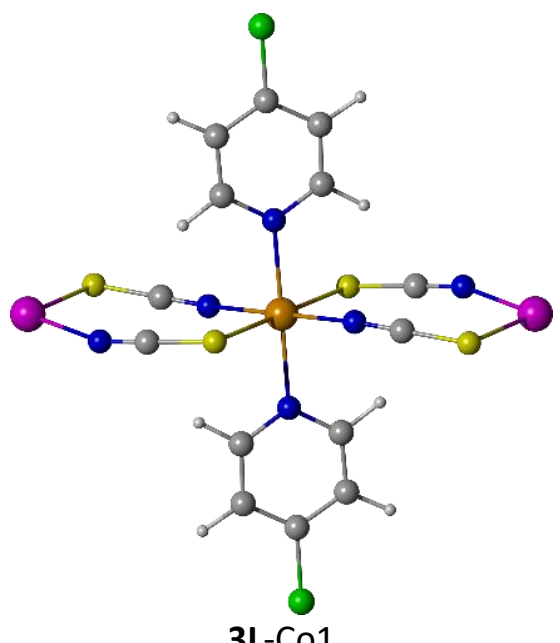

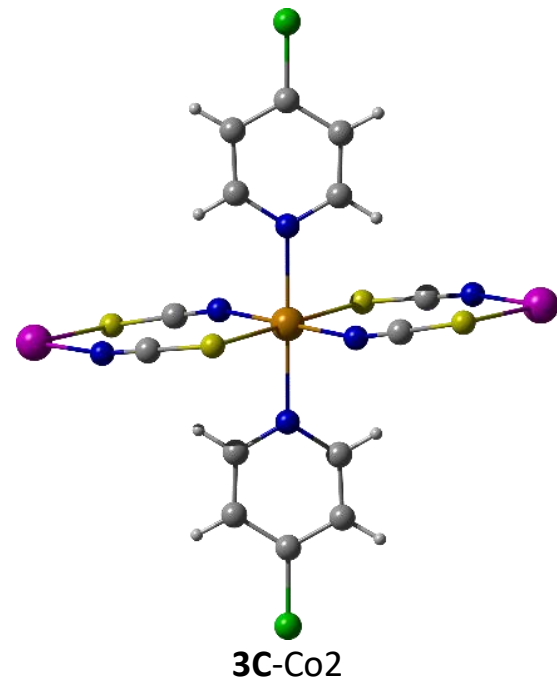

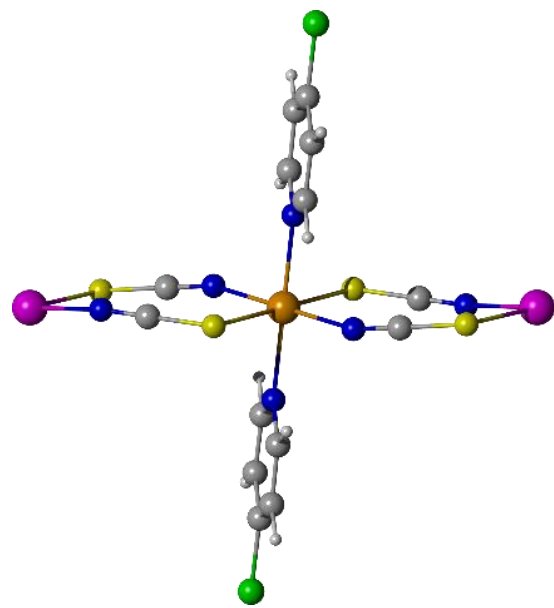

3L-Co2

Figure S31. Mononuclear structural models $\left[\mathrm{CoZn}_{2}(\mathrm{NCS})_{4}(4 \text {-chloropyridine })_{2}\right]^{2+}$ for $\mathbf{3 C}$ (first row) and $\mathbf{3 L}$ (second row), used in the ab initio calculations. The additional zinc(II) ions attached to compensate the negative charge of the structural models are marked as pink spheres. 
Table S6. Relative CASSCF energies (in $\mathrm{cm}^{-1}$ ) of all quartet and the 12 lowest doublet states for the crystallographically independent cobalt(II) centers in $\mathbf{3 C}$ and $\mathbf{3 L}$

\begin{tabular}{|c|c|c|c|c|c|c|}
\hline $2 S+1$ & Term & Subterm & 3C-Co1 & $3 \mathrm{C}-\mathrm{Co} 2$ & 3L-Co1 & $3 \mathrm{~L}-\mathrm{Co} 2$ \\
\hline \multirow[t]{10}{*}{4} & ${ }^{4} \mathrm{~F}$ & ${ }^{4} \mathrm{~T}_{1 \mathrm{~g}}$ & 0 & 0 & 0 & 0 \\
\hline & & & 604 & 408 & 551 & 696 \\
\hline & & & 629 & 997 & 989 & 1108 \\
\hline & & ${ }^{4} \mathrm{~T}_{2 \mathrm{~g}}$ & 6622 & 5785 & 5402 & 5692 \\
\hline & & & 6631 & 7308 & 7709 & 7897 \\
\hline & & & 8687 & 8775 & 8677 & 8487 \\
\hline & & ${ }^{4} A_{2}$ & 15369 & 15418 & 15461 & 15446 \\
\hline & ${ }^{4} \mathrm{p}$ & ${ }^{4} \mathrm{~T}_{1 \mathrm{~g}}$ & 22259 & 21747 & 21538 & 21392 \\
\hline & & & 23281 & 22321 & 22238 & 22774 \\
\hline & & & 23372 & 25497 & 26402 & 25896 \\
\hline \multirow[t]{12}{*}{2} & ${ }^{2} G+{ }^{2} P$ & & 13046 & 12341 & 11834 & 12260 \\
\hline & & & 14562 & 15467 & 16173 & 15922 \\
\hline & & & 18593 & 17982 & 17564 & 18188 \\
\hline & & & 19491 & 19228 & 18429 & 18694 \\
\hline & & & 19751 & 19299 & 19121 & 19358 \\
\hline & & & 19778 & 19770 & 20156 & 20078 \\
\hline & & & 20629 & 20662 & 20820 & 20845 \\
\hline & & & 20656 & 21250 & 21289 & 21374 \\
\hline & & & 24805 & 24627 & 24342 & 24444 \\
\hline & & & 25045 & 24697 & 24393 & 24840 \\
\hline & & & 25154 & 24767 & 24697 & 24864 \\
\hline & & & 25251 & 25132 & 25068 & 25220 \\
\hline
\end{tabular}


Table S7. Relative CASPT2 energies (in $\mathrm{cm}^{-1}$ ) of all quartet and the 12 lowest doublet states for the crystallographically independent cobalt(II) centers in $\mathbf{3 C}$ and $\mathbf{3 L}$

\begin{tabular}{|c|c|c|c|c|c|c|}
\hline $2 S+1$ & Term & Subterm & 3C-Co1 & $3 \mathrm{C}-\mathrm{Co} 2$ & 3L-Co1 & 3L-Co 2 \\
\hline \multirow[t]{10}{*}{4} & ${ }^{4} \mathrm{~F}$ & ${ }^{4} \mathrm{~T}_{1 \mathrm{~g}}$ & 0 & 0 & 0 & 0 \\
\hline & & & 841 & 506 & 580 & 708 \\
\hline & & & 838 & 946 & 823 & 982 \\
\hline & & ${ }^{4} \mathrm{~T}_{2 \mathrm{~g}}$ & 7320 & 6894 & 6359 & 6699 \\
\hline & & & 7346 & 8444 & 8702 & 8978 \\
\hline & & & 9998 & 9942 & 9672 & 9499 \\
\hline & & ${ }^{4} A_{2}$ & 17640 & 17636 & 17566 & 17548 \\
\hline & ${ }^{4} \mathrm{p}$ & ${ }^{4} \mathrm{~T}_{1 \mathrm{~g}}$ & 20104 & 19287 & 19039 & 18853 \\
\hline & & & 20628 & 20137 & 20011 & 20604 \\
\hline & & & 20714 & 23257 & 24219 & 23628 \\
\hline \multirow[t]{12}{*}{2} & ${ }^{2} G+{ }^{2} P$ & & 10566 & 9727 & 9139 & 9578 \\
\hline & & & 11802 & 12652 & 13420 & 13116 \\
\hline & & & 16773 & 16059 & 15545 & 16064 \\
\hline & & & 16858 & 16917 & 16297 & 16593 \\
\hline & & & 17307 & 16681 & 16510 & 16732 \\
\hline & & & 17351 & 17048 & 17427 & 17322 \\
\hline & & & 17925 & 17975 & 18101 & 18138 \\
\hline & & & 17945 & 18415 & 18427 & 18482 \\
\hline & & & 23273 & 21198 & 20674 & 20882 \\
\hline & & & 21425 & 22659 & 21041 & 22500 \\
\hline & & & 21676 & 22008 & 22980 & 22343 \\
\hline & & & 21677 & 21365 & 21235 & 21352 \\
\hline
\end{tabular}

Table S8. Relative RASSI-SO energies (in $\mathrm{cm}^{-1}$ ) of the six lowest Kramers doublets of the ${ }^{4} \mathrm{~T}_{1 \mathrm{~g}}$ ground multiplet for the crystallographically independent cobalt(II) centers in $\mathbf{3 C}$ and $\mathbf{3 L}$

\begin{tabular}{crrrrrr}
\hline Term & Subterm & KD & 3C-Co1 & 3C-Co2 & 3L-Co1 & 3L-Co2 \\
\hline${ }^{4} \mathrm{~F}$ & ${ }^{4} \mathrm{~T}_{1 \mathrm{~g}}$ & 1 & 0 & 0 & 0 & 0 \\
& & 2 & 155 & 174 & 172 & 151 \\
& 3 & 764 & 635 & 749 & 801 \\
& 4 & 1090 & 907 & 1008 & 1056 \\
& 5 & 1249 & 1325 & 1252 & 1346 \\
& & 1387 & 1437 & 1359 & 1457 \\
\hline
\end{tabular}




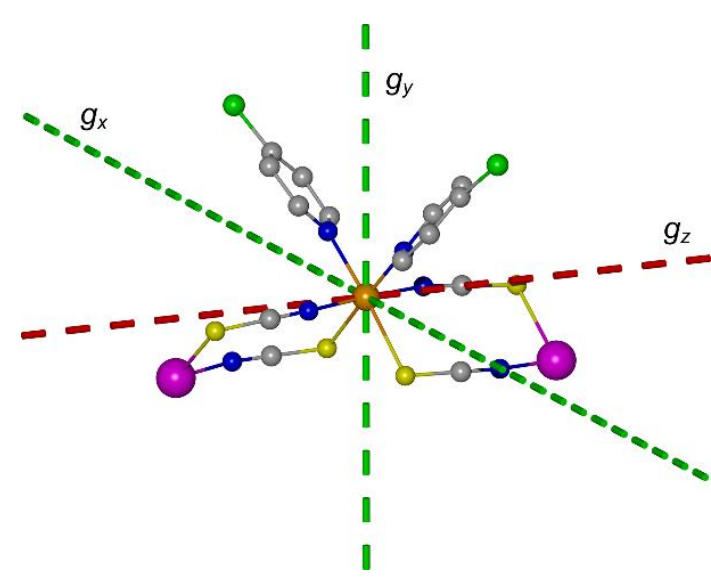

3C-Co1

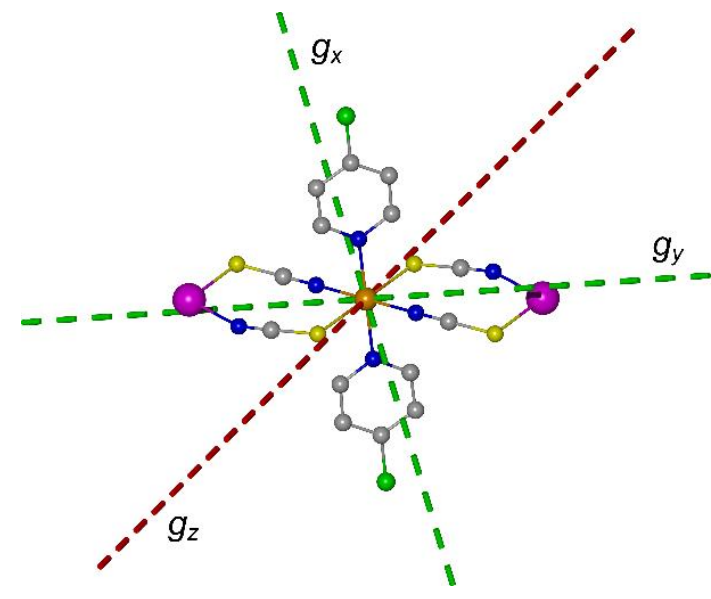

3L-Co1

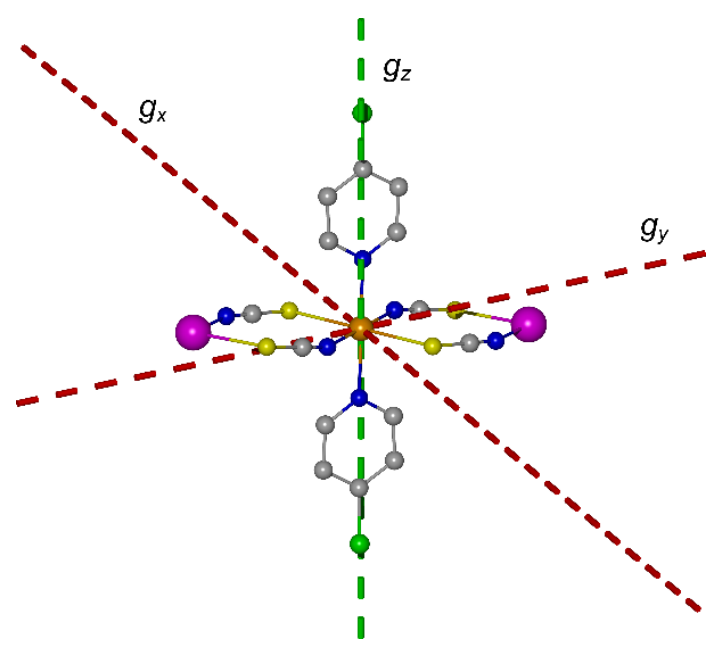

3C-Co2

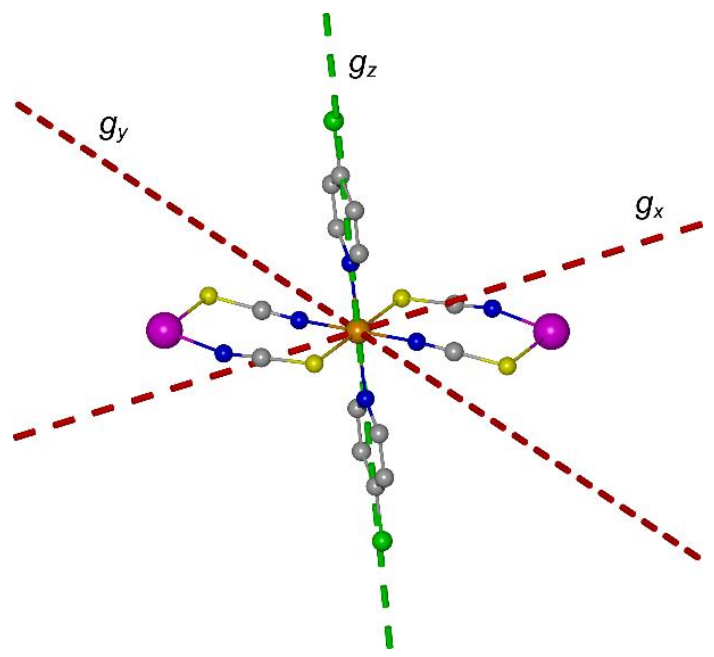

3L-Co2

Figure S32. Representation of the magnetic axes for the ground state Kramers doublet $\left(S_{\text {eff }}=1 / 2\right.$; color code: red - hard axis of magnetization; green - easy axis of magnetization) as obtained from ab initio calculations for the mononuclear model structures of $\mathbf{3 C}$ (first row) and $\mathbf{3 L}$ (second row). 


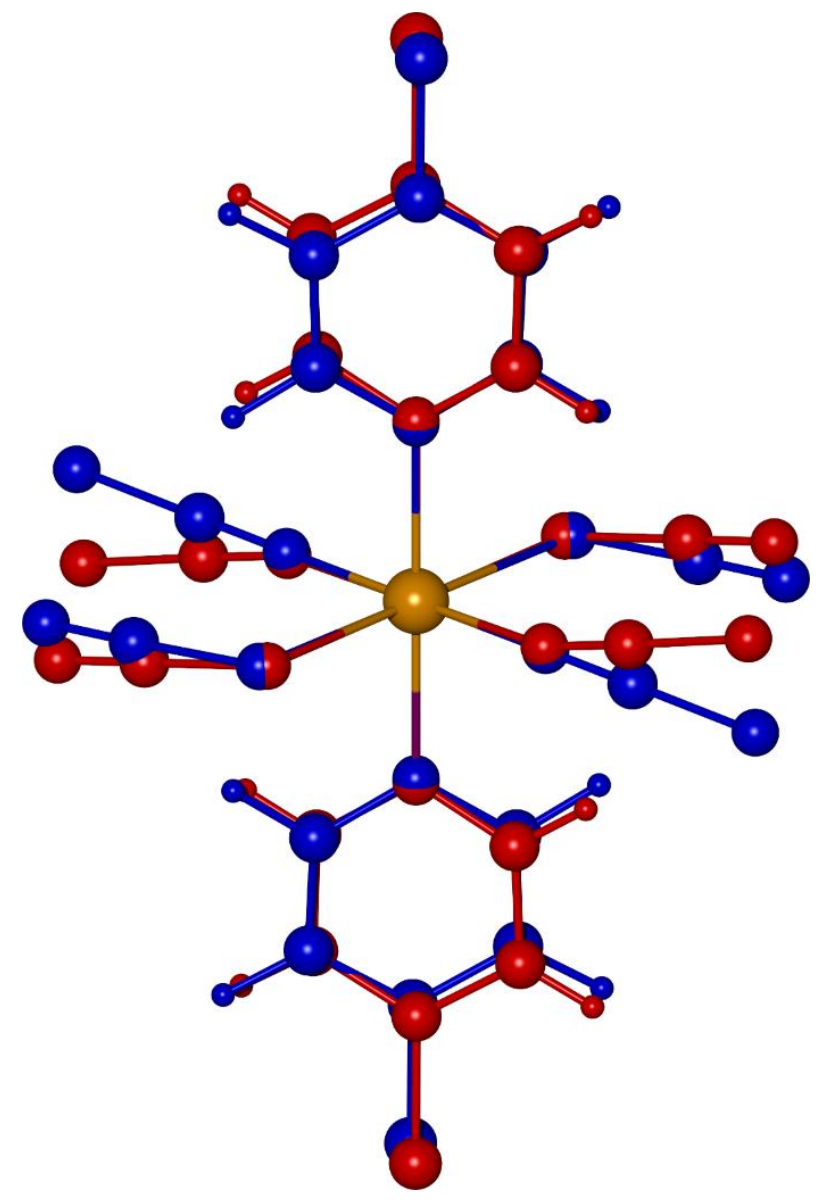

Figure S33. Overlay of the mononuclear cobalt(II) structural models 3C-Co2 (red) and 3L-Co1 (blue). 


\section{A}

$3 C$
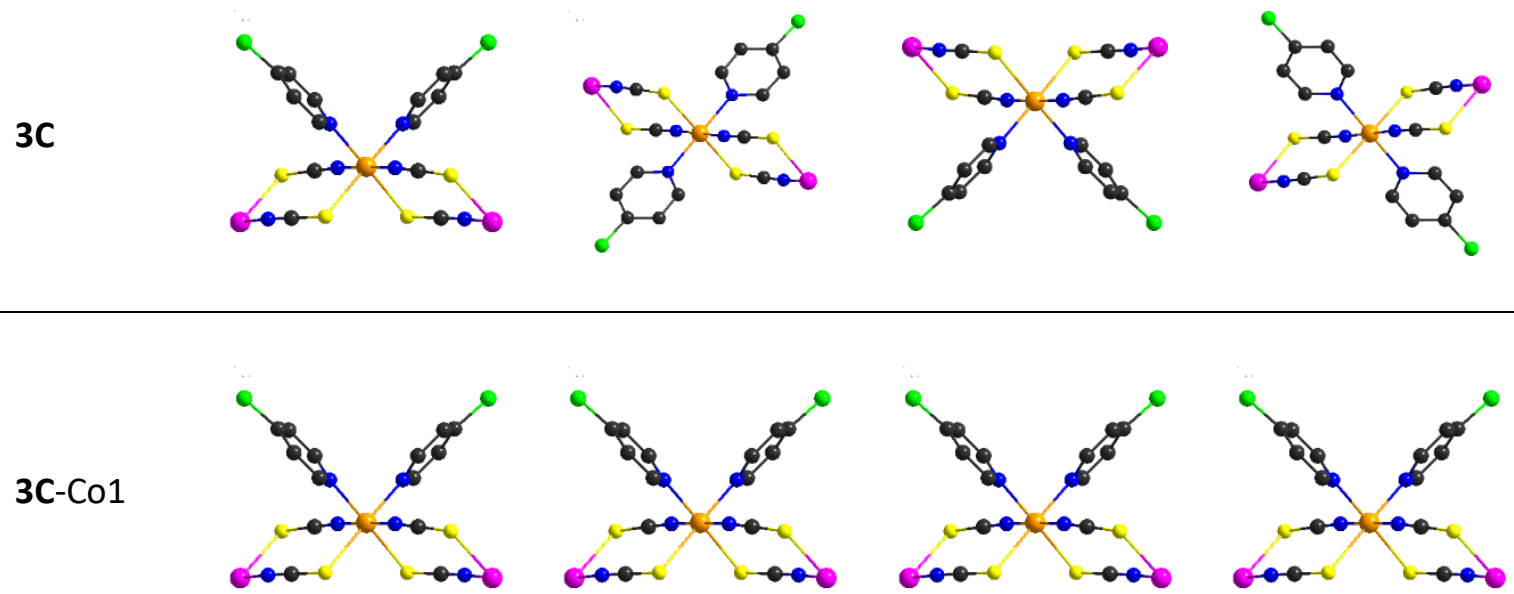

$3 \mathrm{C}-\mathrm{Co} 1 / \mathrm{C} 2$
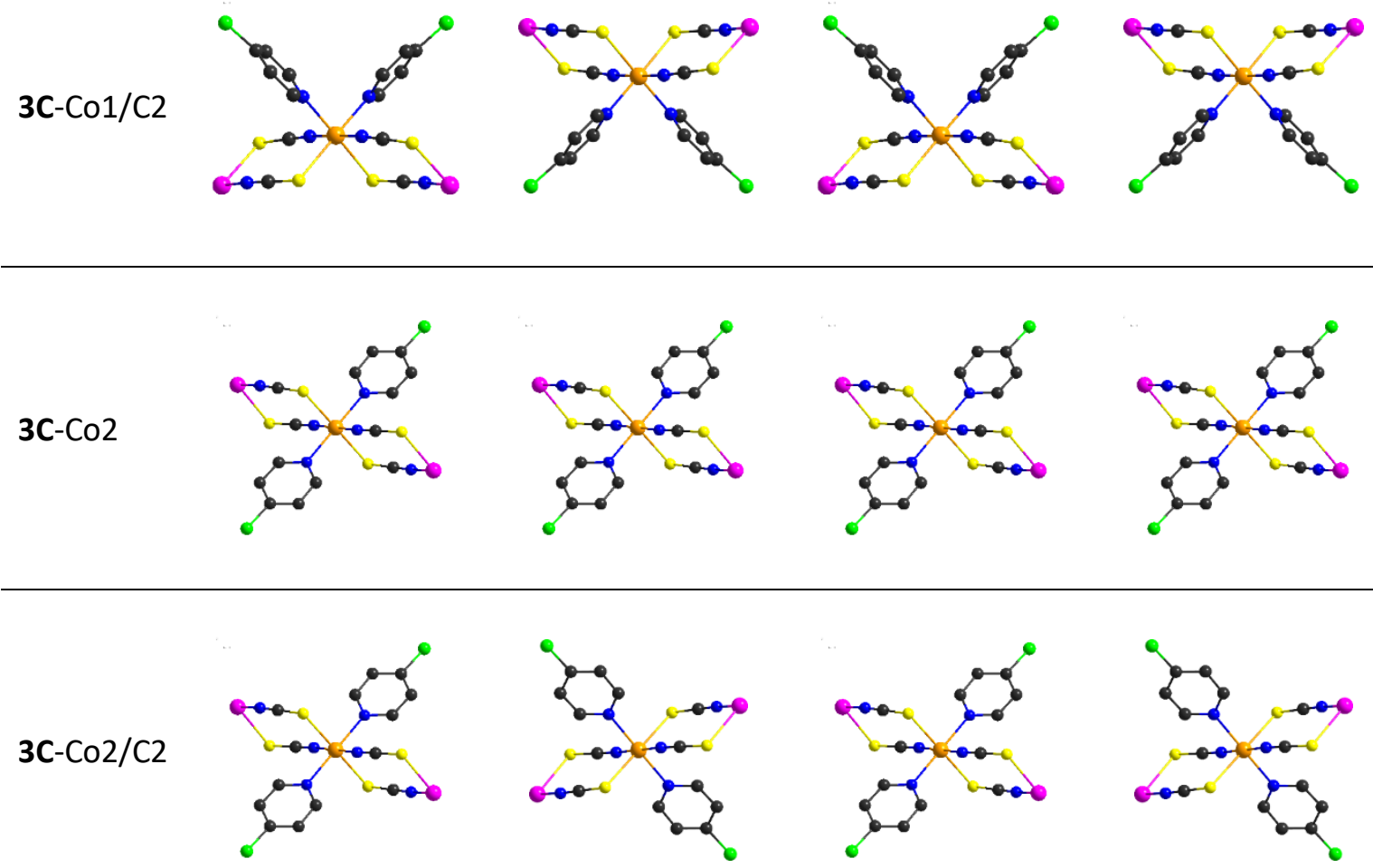

Scheme S1. Graphical definition of $12-$ membered spin rings of the type $[\cdots A \cdots B \cdots C \cdots D \cdots]_{3}$ to simulate hypothetical chains to investigate the influence on the magnetic properties in $\mathbf{3 C}$. 


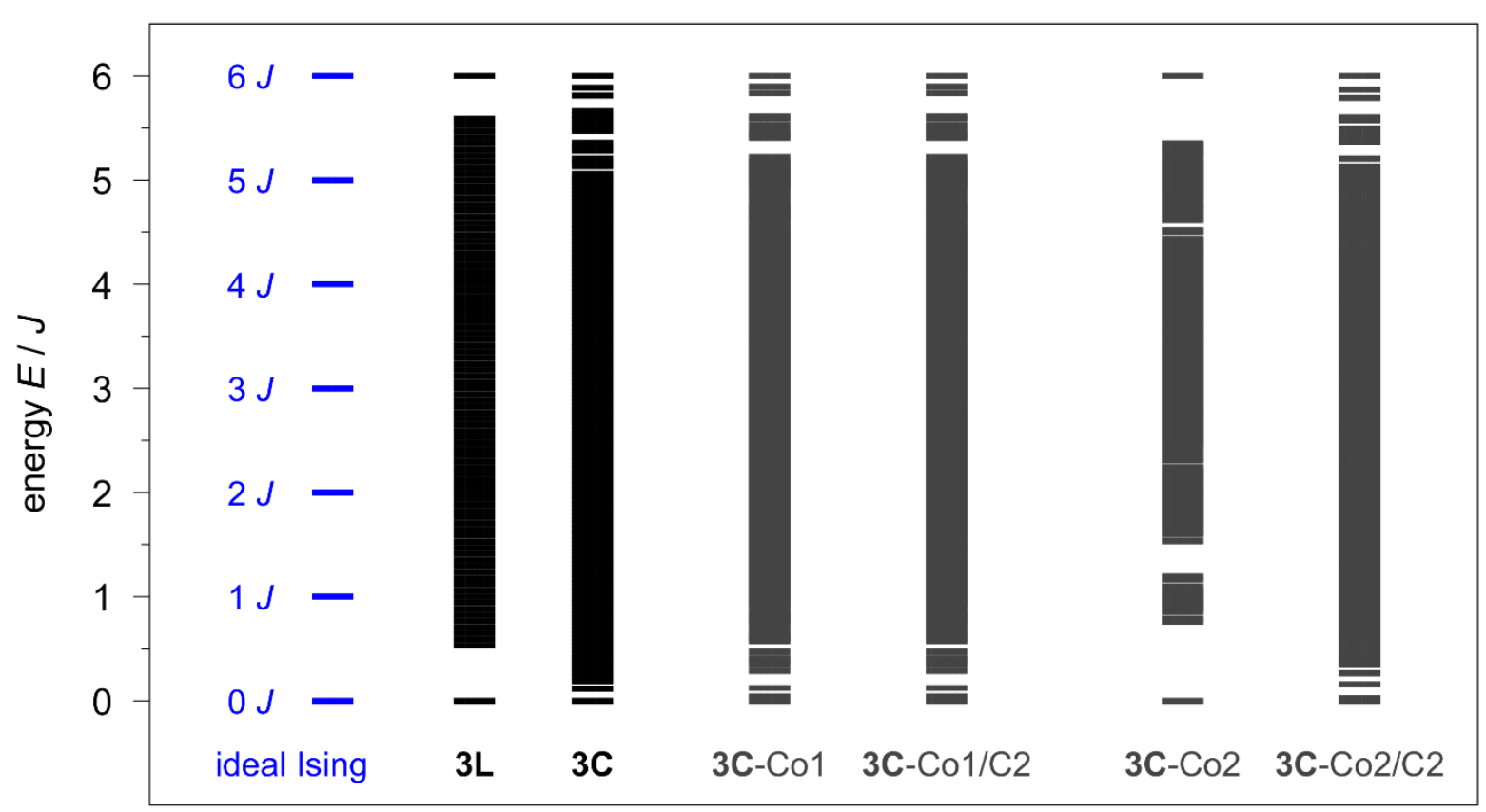

Figure S34. Representation of spin states as obtained by the POLY_ANISO program employing the data from $a b$ initio calculations for the structural models of $\mathbf{3 L}$ and $\mathbf{3 C}$ (black). For all simulations a $12-$ membered spin ring coupling scheme together with a positive coupling constant for the Lines model $\left(J_{i j}>0\right)$ were used. For the sake of comparison, the resulting energy range for all cases has been scaled to $6 J$ where $J$ represents the Ising model coupling constant. The spin states depicted in blue describe the expected multiplet splitting for an ideal Ising anisotropy. Spin states shown in gray represent corresponding calculations based on only one crystallographically independent spin center (3C-Co1 and $3 \mathrm{C}-\mathrm{CO} 2$ ). The simulations denoted as $3 \mathrm{C}-\mathrm{Co} 1 / \mathrm{C} 2$ and $3 \mathrm{C}-\mathrm{Co} / \mathrm{C} 2$ take additionally care of the $C_{2}$ symmetry of the compound (for graphical representation see Scheme S1). 